Linköping Studies in Science and Technology

Dissertation No. 1583

\title{
Microstructural evolution of TiAlN hard coatings at elevated pressures and temperatures
}

\author{
Niklas Norrby
}

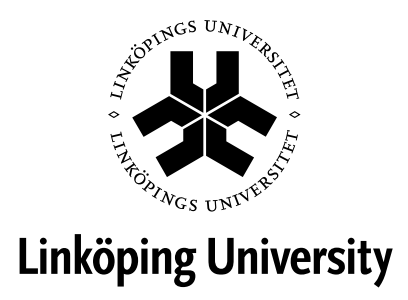

NANOSTRUCTURED MATERIALS DIVISION

DEPARTMENT OF PHYSICS, CHEMISTRY AND BIOLOGY (IFM)

LINKÖPING UNIVERSITY, SWEDEN

LINKÖPING 2014 
The cover image shows nine two-dimensional x-ray diffractograms of TiAlN merged into one quarter circle. Going counterclockwise from an as-deposited sample, the parts show different stages of annealing. The color scheme is chosen to represent the motto "Stort hjärta, hårt arbete".

(C) Niklas Norrby, unless otherwise stated

ISBN: 978-91-7519-372-4

ISSN: 0345-7524

Printed by LiU-Tryck, Linköping, Sweden, 2014 


\section{Abstract}

A typical hard coating on metal cutting inserts used in for example turning, milling or drilling operations is TiAlN. At elevated temperatures, TiAlN exhibits a well characterized spinodal decomposition into coherent cubic TiN and AlN rich domains, which is followed by a transformation from cubic to hexagonal AlN. Using in-situ synchrotron x-ray radiation, the kinetics of the second transformation was investigated in this thesis and the strong temperature dependence on the transformation rate indicated a diffusion based nucleation and growth mechanism. The results gave additional information regarding activation energy of the transformation and the critical wavelength of the cubic domains at the onset of hexagonal AlN. After nucleation and growth, the hexagonal domains showed a striking resemblance with the preexisting cubic AlN microstructure.

During metal cutting, the tool protecting coating is subjected to temperatures of $\sim 900{ }^{\circ} \mathrm{C}$ and pressure levels in the GPa range. The results in this thesis have shown a twofold effect of the pressure on the decomposition steps. Firstly, the spinodal decomposition was promoted by the applied pressure during metal cutting which was shown by comparisons with annealed samples at similar temperatures. Secondly, the detrimental transformation from cubic to hexagonal AlN was shown to be suppressed at elevated hydrostatic pressures. A theoretical pressure/temperature phase diagram, validated with experimental results, also showed suppression of hexagonal AlN by an increased temperature at elevated pressures.

The spinodal decomposition during annealing and metal cutting was in this work also shown to be strongly affected by the elastic anisotropy of TiAlN, where the phase separation was aligned along the elastically softer $<100>$ directions in the crystal. The presence of the anisotropic microstructure enhanced the mechanical properties compared to the isotropic case, mainly due to a shorter distance between the c-AlN and c-TiN domains in the anisotropic case. Further improvement of the metal cutting behavior 
was realized by depositing individual layers with an alternating bias. The individual bias layers exhibited microstructural differences with different residual stress states. The results of the metal cutting tests showed an enhanced wear resistance in terms of both crater and flank wear compared to coatings deposited with a fixed bias. 


\section{Populärvetenskaplig sammanfattning}

I den här avhandlingen presenteras forskningsresultat på en keramisk beläggning, TiAlN (titanaluminiumnitrid), som ligger som ett skyddande skikt på svarvskär. Tjockleken på beläggningen är i storleksordningen av några mikrometer, det vill säga tusendelar av en millimeter. Dessa skär används sedan vid svarvning av metaller, exempelvis vid tillverkning av detaljer till bilmotorer. Vid metallsvarvning uppnås temperaturer runt $900^{\circ} \mathrm{C}$ och det är därför viktigt att använda material som klarar av detta. Svarvskären, som oftast är gjorda av hårdmetall, är visserligen hårda i sig men genom att belägga ytan med TiAlN ökar livslängden betydligt. Detta innebär främst en höjning av produktiviteten genom att svarvhastigheten kan ökas vid bearbetning.

Att just TiAlN är en så pass vanlig beläggning beror bland annat på att vid högre temperaturer sker en förändring i materialet. Detta sker därför att TiN och AlN inte trivs ihop varpå en segregation, till AlN- och TiN-rika områden med en kubisk struktur, sker genom ett spinodalt sönderfall. Storleksordningen på områdena är några nanometer, det vill säga miljontedelar av en millimeter vilket gör att hårdheten i materialet ökar. Vid ytterligare temperaturökning växer dock områdena och till slut omvandlas den kubiska AlN till hexagonal AlN, varpå hårdheten minskar.

Förutom höga temperaturer under svarvning utsätts beläggningen också för ett väldigt högt tryck eftersom det är en liten kontaktarea mellan skäret och materialet man svarvar i. Detta tryck är i storleksordningen av ett par GPa vilket motsvarar tiotals ton på en fingerspets. Främst har dock tidigare forskning inte studerat tryckets påverkan på TiAlN utan istället fokuserat på temperaturen. För att studera detta har utrustning dedikerad för högtrycksforskning använts i kombination med studier av beläggningen efter metallsvarvning. Ytterligare karakterisering har kunnat göras med avancerade metoder som transmissions- och svepelektronmikroskopi, röntgendiffraktion och nanoindentation. 
Bland annat har det kunnat visas att ett högt tryck är positivt för TiAlN i två avseenden. Dels sker det gynnsamma spinodala sönderfallet tidigare, men främst gör ett högt tryck att den kubiska fasen av AlN stabiliseras. Således främjar det höga trycket vid metallsvarvning de positiva egenskaper som fås för TiAlN vid de högre temperaturerna. Resultaten i avhandlingen visar också att mikrostrukturen som bildas under det spinodala sönderfallet för vissa sammansättningar styrs av riktningen som de kubiska kristallerna befinner sig. Denna riktningsberoende mikrostruktur ger ett hårdare material jämfört med om den hade varit oberoende av riktningen. Genom att välja rätt parametrar då TiAlN beläggs går det därför att påverka beteendet för skiktet under skärande bearbetning. Slutligen har omvandlingen från kubisk AlN till hexagonal AlN som funktion av temperatur och tid mätts upp $i$ detalj. Resultaten där visar en stark korrelation med aluminiumhalt i TiAlN och omvandlingshastighet där en högre halt ger ett betydligt snabbare förlopp. 
This thesis is a compilation of the results from my doctoral studies between March 2010 and June 2014 in Nanostructured Materials at the Department of Physics, Chemistry and Biology (IFM) at Linköping University. The work has been financed by Seco Tools AB and SSF and has been performed within the project Designed multicomponent coatings (Multifilm). The experimental work has also been performed at the Advanced Photon Source in Argonne, the Bayerisches Geoinstitut in Bayreuth and at Petra III in Hamburg. The introductory chapters of this thesis are based on, and extended from, my Licentiate thesis High Pressure and high temperature behavior of TiAIN (Licentiate thesis No. 1540, Linköping Studies in Science and Technology, 2010) which was presented in June 2012. 



\section{Included papers}

I Pressure and temperature effects on the decomposition of arc evaporated Ti0.6 Al0.4N coatings in continuous turning

N. Norrby, M.P. Johansson, R. M'Saoubi and M. Odén

Surface and Coatings Technology 209 (2012) 203

II High pressure and high temperature stabilization of cubic AIN in Ti0.60 Alo.40N N. Norrby, H. Lind, G. Parakhonskiy, M.P. Johansson, F. Tasnádi, L.S. Dubrovinsky, N. Dubrovinskaia, I.A. Abrikosov and M. Odén Journal of Applied Physics 113 (2013) 053515

III Anisotropy effects on microstructure and properties in decomposed arc evaporated $T i_{1-x} A l_{x} N$ coatings during metal cutting

M.P. Johansson-Jõesaar, N. Norrby, J. Ullbrand, R. M'Saoubi and M. Odén

Surface and Coatings Technology 235 (2013) 181

IV Improved metal cutting performance with bias modulated textured $T_{0.50} A l_{0.50} \mathrm{~N}$ multilayers

N. Norrby, M.P. Johansson-Jõesaar, and M. Odén

Submitted for publication

$\mathrm{V} \quad$ In-situ $x$-ray scattering study of the cubic to hexagonal transformation of $A I N$ in $\operatorname{Tin}_{-x} A l_{x} N$

N. Norrby, L. Rogström, M.P. Johansson-Jõesaar, N. Schell and M. Odén

Accepted for publication in Acta Materialia 


\section{Related but not included paper}

I Microstructure evolution during the isostructural decomposition of TiAIN $-A$ combined in-situ small angle $x$-ray scattering and phase field study

A. Knutsson, J. Ullbrand, L. Rogström, N. Norrby, L.J.S. Johnson,

L. Hultman, J. Almer, M.P. Johansson-Jõesaar, B. Jansson and M. Odén

Journal of Applied Physics 113 (2013) 213518 


\section{My contribution to the papers}

I I took part in the planning of the project and participated during the depositions and most of the metal cutting tests. I performed all characterizations and wrote the paper.

II I took part in the planning of the project and participated during the depositions and most of the HPHT experiments. I performed all characterizations and wrote the paper (except section II.B)

III I took part in the planning of the project and participated during most depositions and metal cutting tests. I performed the nanoindentation, parts of the TEM work and wrote parts of the paper.

IV I took part in the planning of the project and participated during most depositions and metal cutting tests. I performed all characterizations and wrote the paper.

V I planned everything, performed all characterizations and wrote the paper. 



\section{Acronyms and symbols}

\begin{tabular}{|c|c|}
\hline A & Area \\
\hline$a_{p}$ & Depth of cut \\
\hline $\mathrm{A}_{\mathrm{z}}$ & Zener's anisotropy factor \\
\hline b & Reciprocal primitive basis vector \\
\hline B & Zone axis \\
\hline bcc & Body centered cubic \\
\hline $\mathrm{C}_{\mathrm{ij}}$ & Elastic stiffness constants \\
\hline c- & Cubic structure \\
\hline CVD & Chemical vapor deposition \\
\hline DAC & Diamond anvil cell \\
\hline $\mathrm{d}_{\mathrm{hkl}}$ & hkl plane spacing \\
\hline $\mathrm{E}_{\mathrm{hkl}}$ & Elastic modulus \\
\hline $\mathrm{E}_{\mathrm{a}}$ & Activation energy \\
\hline EDS & Energy dispersive $\mathrm{x}$-ray spectroscopy \\
\hline $\mathrm{f}$ & Cutting feed \\
\hline fcc & Face centered cubic \\
\hline FIB & Focused ion beam \\
\hline G & Gibbs free energy \\
\hline G & Reciprocal lattice vector \\
\hline GD & Growth direction \\
\hline $\mathrm{H}$ & Hardness \\
\hline h- & Hexagonal structure \\
\hline $\mathrm{h}_{\mathrm{c}}$ & Contact depth \\
\hline$h_{\max }$ & Total displacement \\
\hline $\mathrm{h}_{\mathrm{s}}$ & Surface displacement \\
\hline HAADF & High angle annular dark field \\
\hline hcp & Hexagonal close packed \\
\hline hkl & Miller index \\
\hline HR & High resolution \\
\hline
\end{tabular}




\begin{tabular}{ll} 
I & Intensity \\
IP & In plane direction \\
$\mathbf{k}$ & Incident wave vector \\
$\mathbf{k}$ & Scattered wave vector \\
KJMA & Kolmogorov-Johnson-Mehl-Avrami \\
MA & Multi anvil press \\
n & Avrami constant \\
P & Pressure \\
PVD & Physical vapor deposition \\
$P_{\text {max }}$ & Maximum load \\
q & Scattering vector \\
R & Molar gas constant \\
r & Radius \\
RG & Radius of gyration \\
RT & Room temperature \\
SAXS & Small angle x-ray scattering \\
SEM & Scanning electron microscope \\
STEM & Scanning transmission electron microscope \\
S & Contact stiffness \\
T & Temperature \\
TC & Texture coefficient \\
TEM & Transmission electron microscope \\
v $_{c}$ & Cutting speed \\
WAXS & Wide angle x-ray scattering \\
XRD & X-ray diffraction \\
Z & Atomic number \\
$\varepsilon$ & Impingement parameter \\
$\varepsilon$ & Strain \\
$\lambda$ & Wavelength \\
$\nu$ & Poisson's ratio \\
$\varphi$ & Rotation angle \\
$\psi$ & Tilt angle \\
$2 \theta$ & Scattering angle \\
& \\
\hline &
\end{tabular}




\section{Acknowledgments}

- My supervisor, Professor Magnus Odén, for giving me the opportunity to do this journey and for all your support over the years. You have always had time to talk, not only about work related but also about other (funnier) things. Someday I am certain that you will be in Cloetta Center and see LHC raise the Le Mat Trophy.

- My co-supervisor, Dr. Mats Johansson, for your guidance in most of the experimental matters during these years. You always have plenty of ideas with the attitude that everything is possible, I really look forward to keep having you as a colleague.

- My collaborators outside the group, Professor Leonid Dubrovinsky, Professor Natalia Dubrovinskaia and Dr. Gleb Parakhonskiy at Bayerisches Geoinstitut in Bayreuth and Professor Igor Abrikosov, Dr. Ferenc Tasnádi and Hans Lind in Theoretical Physics at IFM for the contributions to Paper II.

- Dr. Axel Knutsson, for teaching me the fun sides of being a PhD student. But never forget that you only became Race of the Ring Master at APS because some other synchrotron scientists had put out speed retardant trash cans when I did my attempt.

- Dr. Jianqiang Zhu, thank you for all the excellent Chinese food and the invitation to your wedding in China. It is always a pleasure watching you prepare those delicious dumplings (far better than drunken shrimps). Make sure you stay in Sweden for a long time! 
- Dr. Lina Rogström, Dr. Jeremy Schroeder, Daniel Ostach and Dr. Norbert Schell for all the fun days and nights at the Petra III beam line station. I will joyfully remember all the pizza and chocolate eating, the didgeridoo "playing" and the accidental fires in the station.

- My colleagues in the Nanostructured Materials Group for all the nice coffee breaks. Also a big thanks to Therese Dannetun, you have surely been patient when reminding me about everything that I had forgotten to do.

- My colleagues in the Thin Film, Plasma and Theoretical Physics groups for providing a nice working environment, both in the coffee room and in the lab.

- Everyone at Seco Tools AB for being so friendly and helpful every time I visit Fagersta, especially Dr. Rachid M'Saoubi who contributed to Paper I.

- Friends and family, for reminding me about the world outside the university. Mina föräldrar för all er uppmuntran trots att ni nog inte riktigt vet vad jag pysslar med. Ante och Tobben för att det alltid är lika kul när vi träffas alla tre. Jag hoppas att vi aldrig blir för gamla för att "slåss" eller sitta uppe hela nätterna och spela Chicago.

- Amelie, för att du gör mig lycklig (även om det är lite oroväckande att du också är på väg att bli en svarvnörd). 


\section{Contents}

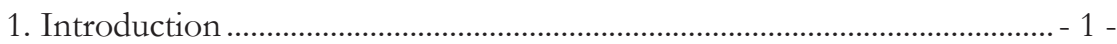

1.1 Aim of the thesis ................................................................................. 1 -

1.2 Outline of the thesis .......................................................................... 2 -

2. Materials science $-\mathrm{a}$ background ................................................................... 3 -

2.1 Phases and phase transformations ……………………………...... - 3 -

2.2 Hardening mechanisms....................................................................... - 8 -

3. Coating deposition ………………………………………………………... 11 -

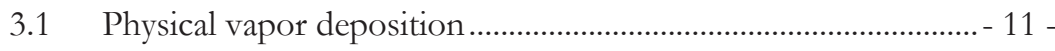

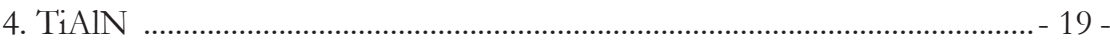

4.1 Spinodal decomposition of TiAlN ............................................... 20 -

4.2 Nucleation and growth of h-AlN ..................................................... 23 -

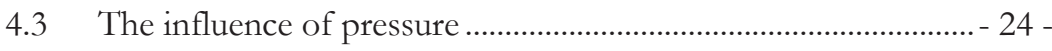

5. Characterization methods ............................................................................- 27 -

5.1 X-ray diffraction.............................................................................. 27 -

5.2 Electron microscopy …………………………………………....- 32 -

5.3 Nanoindentation ........................................................................... 39 -

6. High pressure techniques..............................................................................- 41 -

6.1 Diamond anvil cell .............................................................................- 41 -

6.2 Multi anvil press …………………………………………………...... 43 -

6.3 Sample preparation ........................................................................ 45 - 
7. Metal machining .........................................................................................- 47 -

7.1 Temperature distribution ...................................................................- 47 -

7.2 Stress distribution............................................................................. 49 -

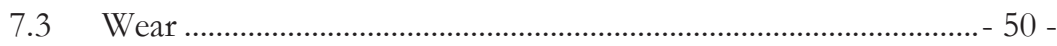

7.4 Chemical interactions ................................................................... 53 -

8. Summary of included papers......................................................................- 55 -

8.1 Paper I ....................................................................................... 55 -

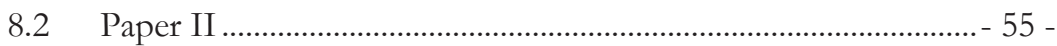

8.3 Paper III.......................................................................................... 56 -

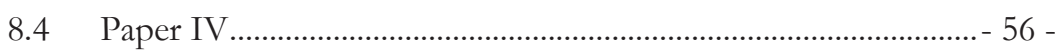

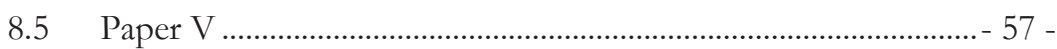

9. Contributions to the field …………………………………………………...... 59 -

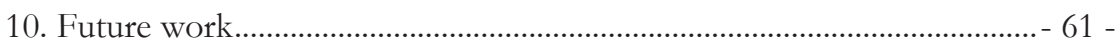

10.1 In-situ pressure dependence of TiAlN ………………………......- 61 -

10.2 Pressure dependence of quaternary coatings ................................. 61 -

10.3 Kinetic description of quaternary coatings ..................................... 62 -

10.4 In-situ annealing in TEM .................................................................. 62 -

10.5 Hot hardness of coatings ..................................................................- 62 -

11. References …………………………………………………………………… 65 -

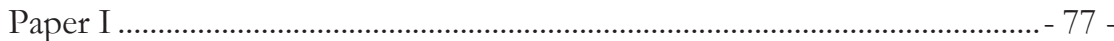

Paper II............................................................................................ 85 -

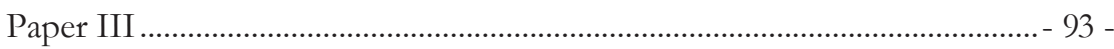

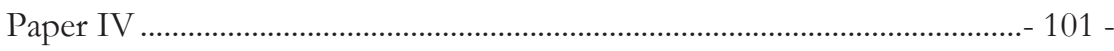

Paper V ..................................................................................................- 121 - 


\section{Introduction}

Coatings, or thin films, are encountered everywhere in a wide variety of applications, including protection against wear and corrosion or for electrical, anti-reflective and decorative purposes. The coatings studied in this thesis exhibit high hardness at elevated temperatures which makes them suitable for the use as protective coatings on cutting tools, for example on cemented carbide inserts. The inserts are mainly used in metal cutting operations, e.g., turning, milling or drilling operations with a huge selection of end products. There is a constant request from the industry of an increased productivity which results in a demand for higher cutting speeds and improved coatings, able to fulfil these requirements, are thus necessary.

The work presented in this thesis has been focused on the ternary ceramic compound TiAlN, which has been used in the metal cutting industry since the 1980s [1,2]. TiAlN was the successor of TiN and was introduced to improve the poor oxidation behavior of TiN at temperatures exceeding $500{ }^{\circ} \mathrm{C}[3,4]$. Additionally, TiAlN exhibits not only a better oxidation behavior compared to TiN at elevated temperatures but also an age hardening behavior [5-11]. The age hardening is a consequence of an isostructural spinodal decomposition into TiN and AlN rich nanostructured domains which has its origin in the immiscibility of TiN and AlN. With further annealing, the spinodal decomposition is followed by a second transformation from cubic AlN into its thermodynamically stable hexagonal phase. The consequences of the hexagonal transformation are detrimental for the mechanical properties and thus the metal cutting behavior [12].

\subsection{Aim of the thesis}

During a typical metal cutting operation, temperatures around $900{ }^{\circ} \mathrm{C}$ and pressure levels in the GPa region are commonly reached [13-15]. However, the large number of previous studies have focused on the temperature 
properties alone and neglected the effect of pressure on the decomposition steps. Also, the main focus has to a large extent been on the spinodal decomposition of TiAlN despite the deteriorating effect on the mechanical properties induced by the hexagonal transformation.

In this thesis, the effect of high temperature and high pressure has been studied by various means of experimental setups. These include dedicated instruments for high pressure research and real life cutting tests, in combination with electron microscopy, $\mathrm{x}$-ray diffraction and nanoindentation. Also presented in the thesis are detailed kinetic results of the hexagonal transformation obtained from in-situ synchrotron $\mathrm{x}$-ray diffraction. All coatings in this thesis have been synthesized by cathodic arc evaporation in an industrial scale deposition system.

\subsection{Outline of the thesis}

An introduction to important concepts in materials science relevant for this thesis is given in Chapter 2. This is followed by a deeper description about the deposition of the coatings in Chapter 3. Chapter 4 describes the material system, TiAlN, studied in this thesis in more detail after which the characterization techniques are described in Chapter 5. The high pressure techniques used in this thesis and an introduction to metal machining are introduced in Chapter 6 and Chapter 7 respectively. The final chapters present a summary of the appended papers, contributions to the field and some suggestions to future work. The remaining part of the thesis is then dedicated to the appended papers. 


\section{Materials science - a background}

A detailed understanding of macroscopic material properties, such as hardness and thermal properties, often requires information on the atomic level. Important questions include why phase transformations occur and what the effect of external parameters such as temperature and pressure is. By gaining insight in this, the possibility arises to control and tailor the material to desired properties. This chapter introduces some of the basic concepts used in materials science which are discussed and used in later chapters.

\subsection{Phases and phase transformations}

The properties of a material often depend on how the atoms are arranged in the material. If the atoms are randomly distributed without a long range ordering, the material is amorphous with glasses as a typical example. Despite the lack of a long range ordering though, amorphous materials may still exhibit a short range ordering [16]. However, many materials are crystalline, i.e., their atoms are arranged in a long range ordered lattice extending in three dimensions. For each periodic lattice, unit cells can be derived for different phases where the most common include the body centered cubic (bcc), face centered cubic (fcc) and hexagonal close packed (hcp).

Dependent on external parameters, such as temperature or pressure, the same material often exists in different phases. One example is iron which at room temperature and ambient pressure is stable in the bcc structure, but transforms into the fcc structure at temperatures above $900{ }^{\circ} \mathrm{C}$. This is followed by a final transformation into bcc again at temperatures above $1400{ }^{\circ} \mathrm{C}$ before melting. A transition from bcc iron to hcp iron is also obtained at an elevated hydrostatic pressure and room temperature [17-19].

The stable phase for a material is governed by thermodynamics, i.e., the stable phase exists in the state with a minimized free energy. An example can be seen in Figure 1 where the system's energy is lowest at position C. There is 
hence a driving force for a system at position A to transform to position C. However, as the system is situated in a local minimum at position $A$, it is said to be in a metastable state. In order to transform from its metastable state to the most energetically favorable state, a passing of the energy barrier marked in B must be accomplished. Small fluctuations from position A will thus only serve to increase the system's energy.

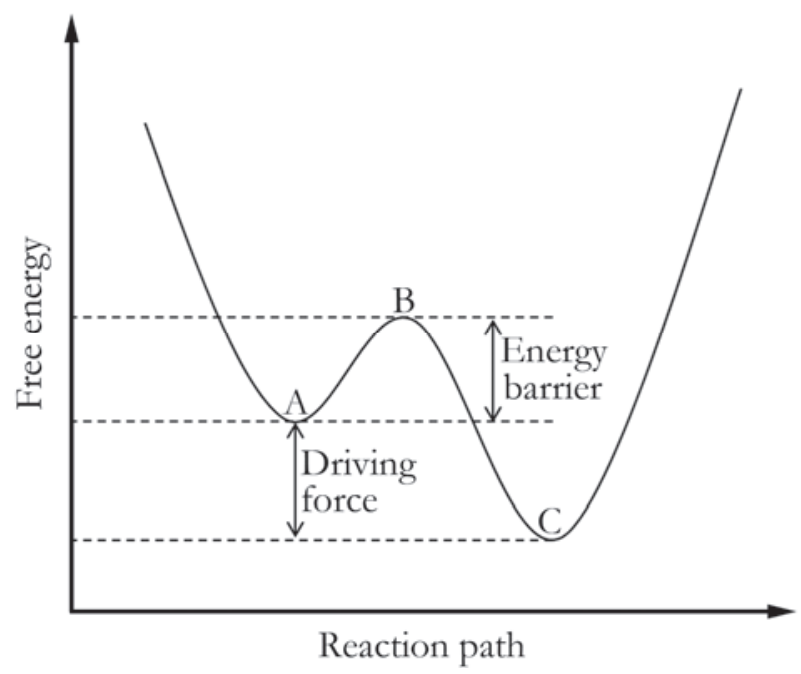

Figure 1. Schematic free energy along a reaction path. The local minimum at position $\mathrm{A}$ indicates a metastable state whereas the global minimum at position $\mathrm{C}$ shows a stable configuration. The passing of the energy barrier in $\mathrm{B}$ is required to reach position $\mathrm{C}$.

In addition to thermodynamics, phase transformations are also often governed by kinetics, i.e., the diffusion of atoms, where low temperatures limit thermodynamically driven processes. Exceptions to this include diffusionless phase transformations such as the martensitic transformation [20]. When all the prerequisites are met for a transition, it can for example occur through nucleation and growth or spinodal decomposition. Both of them are present in the decomposition of TiAlN, see Chapter 4 for details. 


\subsubsection{Nucleation and growth}

If the energy of the system can be lowered by the introduction of a new phase, with a composition different from the matrix, the new phase must first nucleate before any growth process starts. The nucleation is either homogenous, which takes place in a uniform solution, or heterogeneous where the nucleation begins at grain boundaries or impurities.

If it is assumed that a homogenous nucleation initiates with a spherical nuclei (with radius $r$ ), there is an increase in energy proportional to the surface energy and hence to $r^{2}$. For a small nucleus, this is a dominating energy term over the energy gain, which is proportional to the volume and $r^{3}$. Hence, a small compositional fluctuation in the mixture will increase the total energy. Homogenous nucleation therefore usually only occurs after super cooling, i.e., when the gain in energy due to the nucleation is very large. Once the nucleus has started to grow in size, the energy gain dominates over the energy increase. Thus, after the radius of the nucleus has exceeded a critical value, the growth can proceed. The surface energy is a less contributing factor at heterogeneous growth due the reduced surface of the new nucleus and nucleation is hence most often heterogeneous. Still, there is a nucleation barrier to climb and small compositional fluctuations will be restored. As the nuclei grow, regions surrounding them are soaked from atoms, giving rise to ordinary down-hill diffusion from the matrix.

One of the models describing the kinetics of the nucleation and growth is the Kolmogorov-Johnson-Mehl-Avrami (KJMA) equation [21-24]. It is here presented in its differential form in Eq. (1) and after integration in Eq. (2):

$d f=(1-f) d x$

$f=1-e^{-x}$

where $\mathrm{f}$ is the transformed fraction and $\mathrm{x}$ an Arrhenius expression. For isothermal conditions, the Arrhenius expression is given in Eq. (3) and Eq. (4):

$x=(k t)^{n}$

$k=k_{0} e^{-\frac{E_{a}}{R T}}$

where $\mathrm{k}_{0}$ is a pre-exponential constant, $\mathrm{t}$ the isothermal time, $\mathrm{R}$ the gas constant, $\mathrm{n}$ the Avrami constant, $\mathrm{T}$ the absolute temperature and $\mathrm{E}_{\mathrm{a}}$ the activation energy. Prerequisites for the KJMA equation include an infinitely large bulk with a random homogeneous nucleation. This is generally not fulfilled in most cases but owing to the simplicity of the KJMA equation it is 
widely used among experimentalists for transformations in, e.g., steel [25-27], polymers [28], and ceramic coatings [29]. Due to the prerequisites of a homogenous nucleation there are modified versions of the KJMA equation to account for grain boundary nucleation [30,31]. In Paper $V$, Eq. (1) is modified with an impingement parameter, $\varepsilon$, as is shown in Eq. (5).

$d f=(1-f)^{\varepsilon} d x$

Here, $\varepsilon<1$ is related to a weak impingement and $\varepsilon>1$ to strong impingement. For grain boundary nucleation, strong impingement typically occurs as the transformation rate is slower compared to a homogenous nucleation. The slower transformation rate occurs as the probability of interfering nuclei increases which hinders a further growth. Contrary, weak impingement occurs in systems with a smaller probability of interfering nuclei, for example during growth of nuclei which are well dispersed in relation to each other.

\subsubsection{Spinodal decomposition}

When a solid solution of two immiscible components is obtained, e.g., during physical vapor deposition of TiAlN, the solution is unstable or metastable. In the metastable state, the system has a local minimum in the free energy which is not the case in the unstable state. Spinodal decomposition may only proceed in an unstable system and it thus occurs without the necessity of passing an energy barrier. It was first experimentally observed by Bradley in 1940 [32] but the results could not be explained until 1956 when Hillert published his doctoral thesis [33] with a theoretical description of the spinodal decomposition.

Figure 2 shows a free energy curve where the spinodal is defined within the region with a negative second derivative of the free energy. Inside the spinodal, small compositional fluctuations decrease the energy which is seen in the left inset. The diffusion process during spinodal decomposition is up-hill diffusion, i.e., atoms move towards regions already enriched of that atom. Outside the spinodal, small compositional fluctuations instead increase the energy as is seen in the right inset and the associated transformation is nucleation and growth which proceeds with down-hill diffusion. 


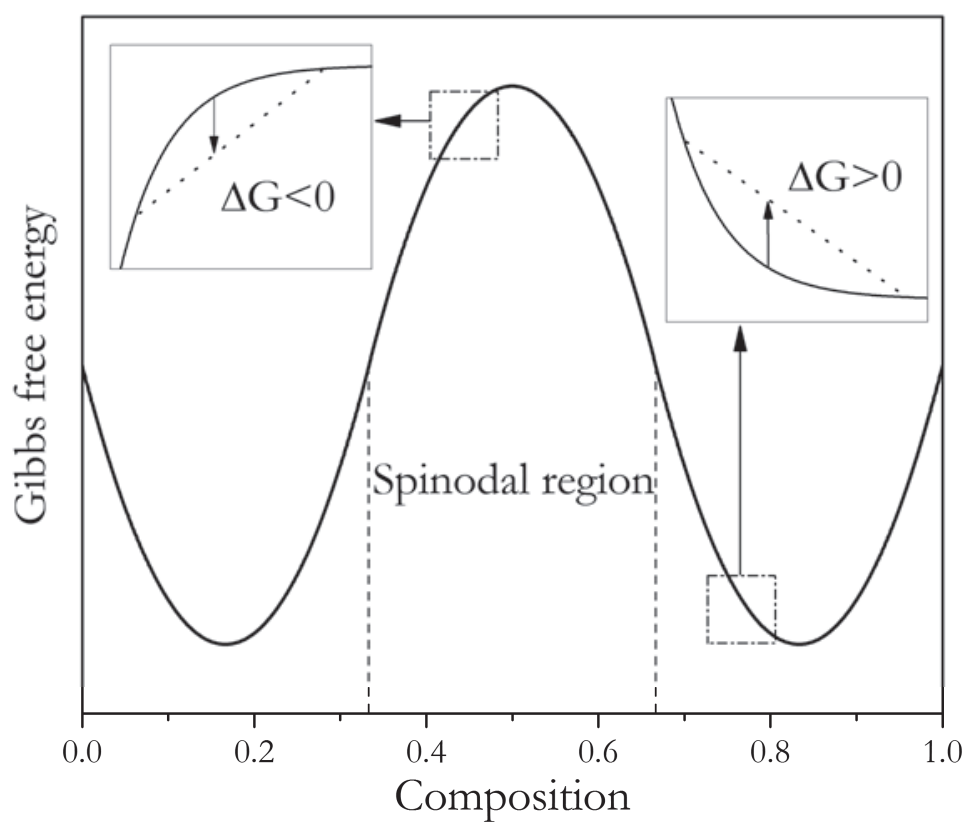

Figure 2. A free energy curve as a function of composition at a given temperature. The second derivative of the curve determines whether an infinitesimal change in composition lowers or increases the total energy.

In the initial stage of the spinodal decomposition, the second derivative of the free energy determines a fastest growing wavelength [34,35] over an extended volume. As the second derivative of the free energy is increased towards zero, the wavelength is maintained but with an increased amplitude. At the zero point, a further decrease in energy is reached by a minimization of the gradient energy and the domains coarsen [36,37].

Typical composition profiles during nucleation and growth, and spinodal decomposition are schematically seen in Figure 3 (a-b). Nucleation and growth yields a few sharp interfaces whereas these occurring after spinodal decomposition are more subtle but over a large volume. Here, Figure 3 shows the spinodal decomposition before any coarsening has occurred. 


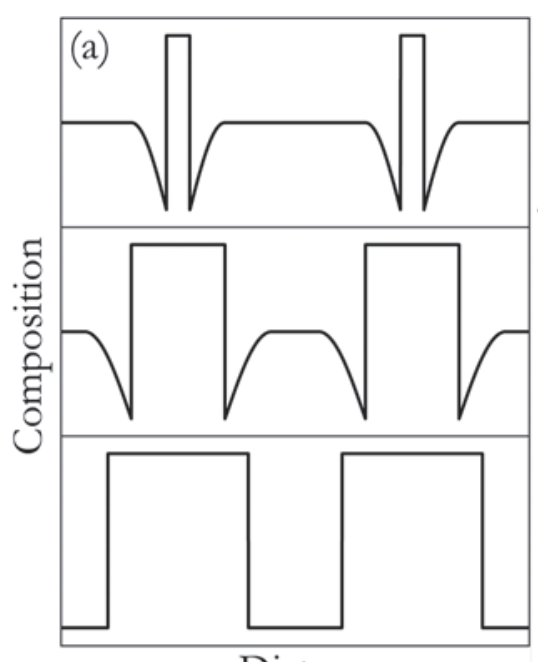

Distance

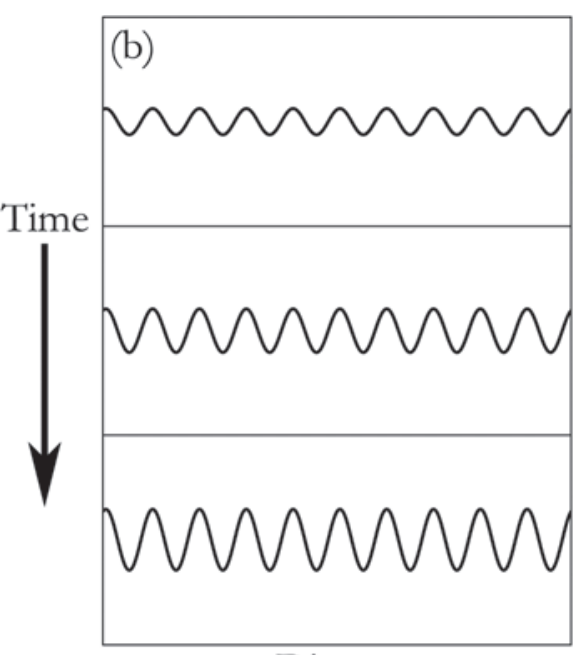

Distance

Figure 3. Schematic composition profiles at different times during (a) nucleation and growth and (b) spinodal decomposition. After [38].

\subsection{Hardening mechanisms}

The hardness of a material is defined as the resistance against plastic deformation [39]. The theoretical hardness of a perfect crystal is however several times higher than what is experimentally observed for most materials [40]. The reason for the lower experimental hardness is the assistance of plastic deformation by dislocation movements in the crystal. Hence, by introducing means to obstruct the dislocations, the hardness of a material is increased. This can be achieved with, e.g., grain boundary hardening [41-43], work hardening [44], solution hardening [45,46] or precipitation hardening $[47,48]$. Precipitation hardening is further described below due to its importance for the TiAlN system at elevated temperatures, see also Chapter 4.

\subsubsection{Precipitation hardening}

If nanometer sized coherent regions with a small lattice mismatch are present in a material, coherency strains are introduced in the lattice. These strain fields interact with the dislocations and additional energy is thus required to pass the particles. Up to a critical radius $\left(\mathrm{r}_{\mathrm{crit}}\right)$, the dislocations pass the particles by cutting and the hardening effect is linear to the particle radius, which is shown schematically in Figure 4. With coarsening above $r_{\text {crit }}$, the coherency may be lost by the introduction of misfit dislocations. Instead of cutting, the 
dislocations now interact with the particles by bowing around them in a process known as Orowan hardening [47,48]. The hardening effect is strongest with finer particles and decreases with an increased radius. Eventually, the hardness effect is lost when the radius is too large, a phenomenon known as over aging.

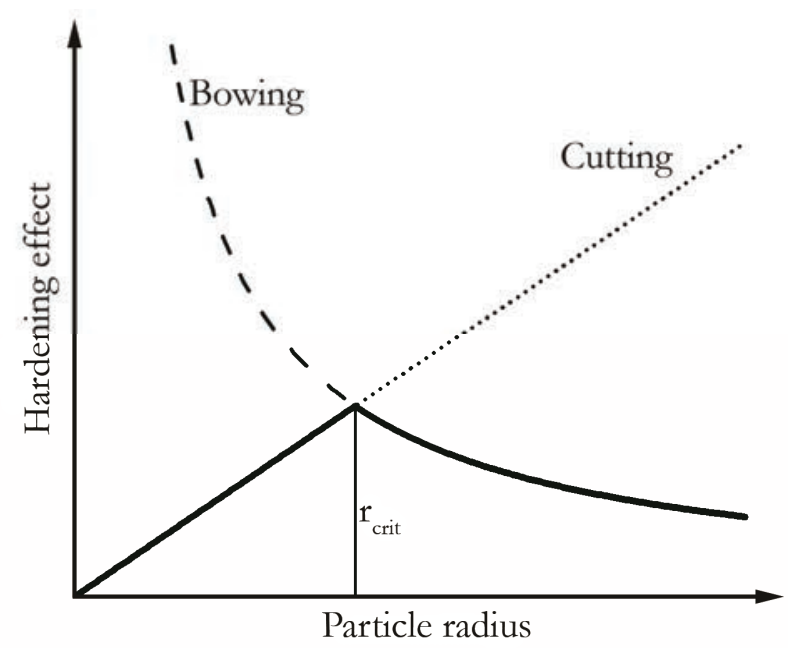

Figure 4. Schematic graphs of the hardening effect as a function of particle radius due to two dislocation interactions with the particles. With $r<r_{\text {crit }}$ the dislocations cut the particles and with $r>r_{\text {crit }}$ the dislocations instead bow around them. 



\section{CHAPTER 3}

\section{Coating deposition}

Coating deposition is divided into chemical vapor deposition (CVD) and physical vapor deposition (PVD), each with a variety of sub-methods. In CVD, the deposition material is introduced into a chamber in the gas phase where it chemically reacts to form the coating, either with the substrate itself or with another gas forming a compound to be grown. In PVD, the deposition material is instead condensed on the substrate which generally requires lower deposition temperature and provides the possibilities to grow metastable or unstable coatings. In this work, all coatings have been deposited with cathodic arc evaporation which is a PVD method.

\subsection{Physical vapor deposition}

The basic principle of all PVD techniques can be divided into four steps. The first step is to synthesize the deposition material which includes a transition from a solid or liquid phase into vapor phase. In the second step, the vaporized material is transported towards the substrate. In the third step, the material is condensed on the substrate surface which is followed by nucleation and growth of the coating. The main difference between different PVD methods, where the two most common are cathodic arc evaporation [49,50] and sputtering [51], is often in the vapor phase synthesis. In sputtering, highly energetic gas ions bombard the target material which then "spits out" (hence the name sputtering) the deposition material towards the substrate. The whole process is a high voltage and low current process with the plasma mainly consisting of gas ions and electrons. In cathodic arc evaporation, which is a low voltage and high current process, the positive species in the plasma are instead mainly metal ions. In the process, the target is locally melted and evaporated by an electric arc [52]. 


\subsubsection{Cathodic arc evaporation}

Cathodic arc evaporation is widely used in the cutting tool industry due to its ability to produce dense and adherent functional coatings. In the beginning of the coating process, the substrates are heated and ion etched before deposition of the coating. An electrical arc is then ignited on the cathode surface with a short circuit by a mechanical trigger, the cathodic arc is thereafter self-sustained and concentrated in small cathode sports on the cathode surface by a magnetic field. The high power density in the cathode spots yields local surface temperatures high enough to melt and evaporate the cathode material [53]. A high degree of ionization [54,55] is achieved by electron collisions in the ionization zone [50] whereupon the ions are attracted by the negatively biased substrate, followed by condensation and growth. By introducing a reactive gas in the chamber, $\mathrm{N}_{2}$, nitride coatings can be grown.

The residual stress in coatings grown with cathodic arc evaporation is a combination of thermal stress and the defect density [56]. The thermal stress, either tensile or compressive, arises during cooling from the deposition temperature to room temperature. The magnitude and sign of the thermal stress is hence dependent on the differences in the coefficient of thermal expansion between the coating and the substrate, in combination with the substrate temperature. Apart from thermal stress, the bombardment of high energy ions causes ion implantation and incorporation of defects in the coatings [56]. This causes a densification of the coatings in combination with compressive residual stresses. As the ion energy is proportional to the substrate bias during deposition, a higher negative bias generally induces a larger compressive stress. An example of this is seen in Table 1, where $T_{0.50} \mathrm{Al}_{0.50} \mathrm{~N}$ and $\mathrm{Ti}_{0.33} \mathrm{Al}_{0.67} \mathrm{~N}$ have been grown with different biases. Upon the bias change from $-35 \mathrm{~V}$ to $-70 \mathrm{~V}$, the compressive stress is almost doubled for both compositions.

Table 1. Residual stress in $\mathrm{Ti}_{0.50} \mathrm{Al}_{0.50} \mathrm{~N}$ and $\mathrm{Ti}_{0.33} \mathrm{Al}_{0.67} \mathrm{~N}$ deposited with a bias of $-35 \mathrm{~V}$ and $-70 \mathrm{~V}$

\begin{tabular}{ccc}
\hline Bias & $\mathrm{Ti}_{0.33} \mathrm{Al}_{0.67} \mathrm{~N}$ & $\mathrm{Ti}_{0.50} \mathrm{Al}_{0.50} \mathrm{~N}$ \\
{$[\mathrm{~V}]$} & {$[\mathrm{GPa}]$} & {$[\mathrm{GPa}]$} \\
\hline-35 & $-2.4 \pm 0.1$ & $-3.3 \pm 0.2$ \\
-70 & $-4.8 \pm 0.2$ & $-6.4 \pm 0.4$ \\
\hline
\end{tabular}


In this work, the coatings were synthesized in an industrial cathodic arc evaporation system. Before depositions, the substrates were cleaned in ultrasonic baths of an alkali solution and alcohol. The system was evacuated to a pressure of less than $2.0 \times 10^{-3} \mathrm{~Pa}$, after which the inserts were sputter cleaned with Ar ions. The depositions were executed in a pure nitrogen atmosphere using compound cathodes comprising $\mathrm{Ti}$ and $\mathrm{Al}$ alloys of different compositions. The substrates, WC:Co inserts and/or thin iron foils, were positioned on a rotating drum.

Three cathode positions exist along the height on each side of the chamber. By mounting TiAl and Ti cathodes on separate sides it is possible to deposit TiAlN/TiN multilayers with layer thickness dependent on the drum's rotational speed [57-59]. It is also possible to mount cathodes with different compositions along the height on each side. With this setup, coatings with different compositions are grown dependent on which cathode the substrates are facing. This method was implemented in Paper I where a pure Ti cathode was used in combination with a $\mathrm{Ti}_{0.50} \mathrm{Al}_{0.50}$ cathode mounted in two positions at different heights in the chamber. This resulted in a gradient composition change of the coatings along the height of the drum, whereupon the desired coating composition could be selected with analytical instruments.

\subsubsection{Coating growth}

During growth, the resulting microstructure is a function of deposition parameters, e.g., coating composition, substrate temperature and ion energy of the impinging species. With higher substrate temperatures, the mobility of the incoming ions increases with a larger grain size as a consequence. Conversely, depositions of amorphous coatings are realized using lower substrate temperatures, since the incoming ions are quenched [60,61]. Depositions in this thesis have been performed with approximate substrate temperatures of $450{ }^{\circ} \mathrm{C}$. This temperature is high enough for crystalline growth but also low enough to enable the growth of unstable coatings.

Controlling the microstructure is also possible with the substrate bias as the ion energy distribution changes. This is exemplified in Figure 5 which shows heat treated $\mathrm{Ti}_{0.50} \mathrm{Al}_{0.50} \mathrm{~N}$ deposited at (a) $-35 \mathrm{~V}$ and (b) $-70 \mathrm{~V}$. The microstructure of the coating deposited with $-35 \mathrm{~V}$ reveals a columnar structure with column widths of a few hundred nanometers. The change in bias to $-70 \mathrm{~V}$ increases the ion energy during bombardment which results in a larger probability for re-nucleation of new grains and thus a smaller grain size [62]. 


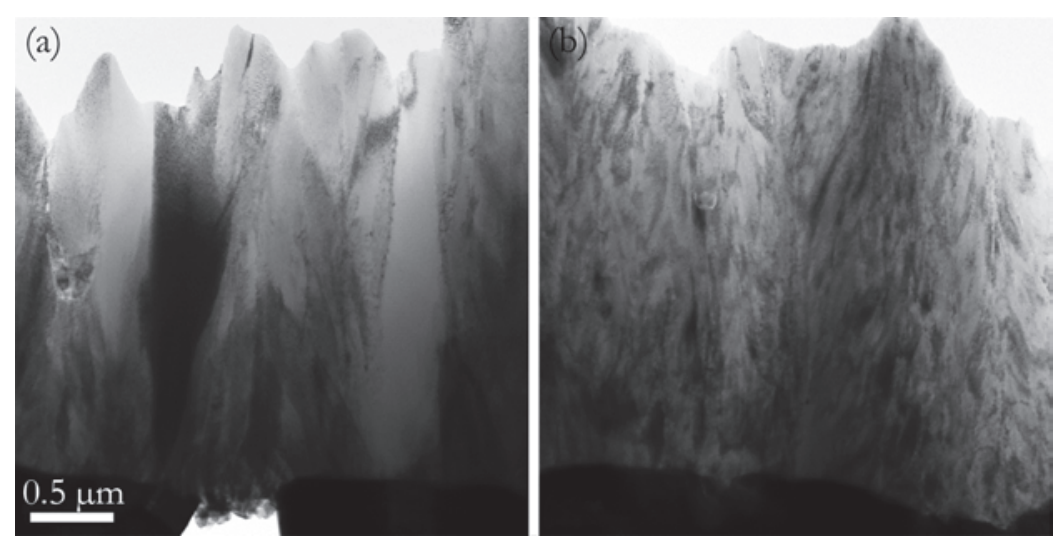

Figure 5. Transmission electron micrographs of $\mathrm{Ti}_{0.50} \mathrm{Al}_{0.50} \mathrm{~N}$ deposited with a bias of (a) $-35 \mathrm{~V}$ and (b) $-70 \mathrm{~V}$.

In general, PVD grown TiAlN exhibits a fiber texture with a preferred orientation controlled by the bias or coating thickness [63-68]. This is exemplified in Figure 6 which shows $\theta-2 \theta$ x-ray diffractograms of ${ }^{1} i_{0.50} \mathrm{Al}_{0.50} \mathrm{~N}$ and $\mathrm{Ti}_{0.33} \mathrm{Al}_{0.67} \mathrm{~N}$ deposited at $-35 \mathrm{~V}$ and $-70 \mathrm{~V}$. A clear suppression of the (200) preferred orientation is seen as a consequence of the bias change from $-35 \mathrm{~V}$ to $-70 \mathrm{~V}$.

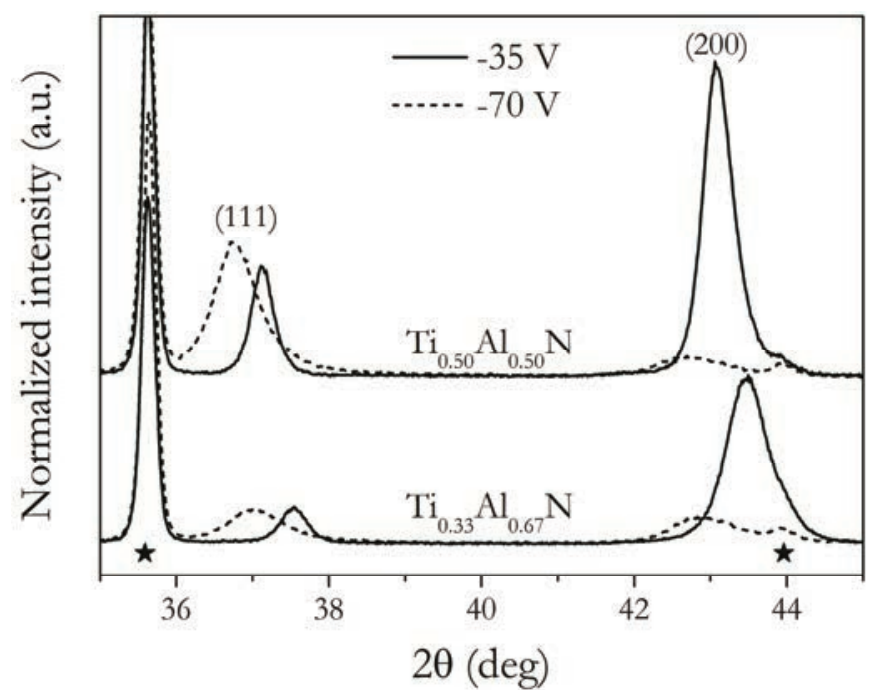

Figure 6. X-ray diffractograms showing the two first cubic peaks of $\mathrm{Ti}_{0.33} \mathrm{Al}_{0.67} \mathrm{~N}$ and $\mathrm{Ti}_{0.50} \mathrm{Al}_{0.50} \mathrm{~N}$ deposited at different bias. The stars mark diffraction peaks from the substrate or sample holder. From Paper IV. 
From the $\theta-2 \theta$ diffractogram, the preferred orientation can be described by the texture coefficient, $\mathrm{T}_{\mathrm{C}}$, which is defined in Eq. (6):

$T_{C}(h k l)=\frac{I_{\text {meas }}(h k l)}{I_{0}(h k l)}\left[\frac{1}{n} \sum_{1}^{n} \frac{I_{\text {meas }}(h k l)}{I_{0}(h k l)}\right]^{-1}$

where $\mathrm{I}_{0}(\mathrm{hkl})$ is the relative intensity for each peak of a randomly oriented sample and $I_{\text {meas }}(\mathrm{hkl})$ the integrated peaks from the $\theta-2 \theta$ measurements in Figure $6 . \mathrm{I}_{0}(\mathrm{hkl})$ have in this work been extracted from synchrotron powder measurements of equivalent compositions. $T_{C}$ as a function of composition and bias is presented in Table 2 for the three most distinguished peaks (111, 200, 220). Because three peaks are used, $T_{C}$ varies between 0 and 3 where 1 corresponds to a random orientation and 3 a complete preferred orientation.

Table 2. Texture coefficients of (111), (200) and (220) reflections in $\mathrm{Ti}_{0.50} \mathrm{Al}_{0.50} \mathrm{~N}$ and $\mathrm{Ti}_{0.33} \mathrm{Al}_{0.67} \mathrm{~N}$ as a function of bias.

\begin{tabular}{ccccc}
\hline & \multicolumn{2}{c}{$\mathrm{Ti}_{0.50} \mathrm{Al}_{0.50} \mathrm{~N}$} & \multicolumn{2}{c}{$\mathrm{Ti}_{0.33} \mathrm{Al}_{0.67} \mathrm{~N}$} \\
& $-35 \mathrm{~V}$ & $-70 \mathrm{~V}$ & $-35 \mathrm{~V}$ & $-70 \mathrm{~V}$ \\
\hline $\mathrm{T}_{\mathrm{C}}(111)$ & 1.20 & 2.49 & 0.93 & 2.03 \\
$\mathrm{~T}_{\mathrm{C}}(200)$ & 1.49 & 0.17 & 1.72 & 0.49 \\
$\mathrm{~T}_{\mathrm{C}}(220)$ & 0.31 & 0.34 & 0.35 & 0.48 \\
\hline
\end{tabular}

The results show a (200) preferred orientation for both compositions after deposition with a bias of $-35 \mathrm{~V}$, slightly stronger for $\mathrm{Ti}_{0.33} \mathrm{Al}_{0.67} \mathrm{~N}$. Upon changing the bias to $-70 \mathrm{~V}$, the growth changes into a (111) preferred orientation with $\mathrm{T}_{\mathrm{C}}>2$ for both composition. Here, $\mathrm{Ti}_{0.50} \mathrm{Al}_{0.50} \mathrm{~N}$ instead shows the strongest preferred orientation compared to $\operatorname{Ti}_{0.33} \mathrm{Al}_{0.67} \mathrm{~N}$. The origin of the change from a (200) to a (111) preferred orientation is discussed in Paper IV and a probable explanation is the altered surface mobility during deposition. As is discussed by Alling et al. [69], the addition of $\mathrm{Al}$ atoms on the surface causes energy barriers on the (200) surfaces which restrains the growth on these over the (111) surfaces. With the increase of the absolute bias to $-70 \mathrm{~V}$, the kinetic energy of the incoming species is increased. Thus, the probability of overcoming the energy barriers increases whereupon the growth is instead restrained on (111) surfaces. This also explains the stronger (111) preferred orientation on $\mathrm{Ti}_{0.50} \mathrm{Al}_{0.50} \mathrm{~N}$ compared to $\mathrm{Ti}_{0.33} \mathrm{Al}_{0.67} \mathrm{~N}$. The reason is that during deposition of TiAlN, the ratio of $\mathrm{Ti}^{2+}$ ions over $\mathrm{Al}^{2+}$ in the plasma is larger [70] and hence the overall ion energy distribution is 
increased with the low $\mathrm{Al}$ content coating. This effect is further pronounced by the reduced amount of $\mathrm{Al}$ on the surfaces in $\mathrm{Ti}_{0.50} \mathrm{Al}_{0.50} \mathrm{~N}$.

A full description of the preferred orientation, e.g., for determining fiber texture or epitaxial growth, the texture coefficient is not sufficient and for this, pole figures or orientation distribution functions are needed. Examples of pole figures for $\mathrm{Ti}_{0.50} \mathrm{Al}_{0.50} \mathrm{~N}$ are seen in Paper $\mathrm{IV}$, showing the fiber texture of TiAlN.

\subsubsection{Droplets}

The largest disadvantage with cathodic arc evaporation is the generation of droplets, also known as macroparticles. They originate from the molten pool of the cathode material due to the extremely high temperatures in the cathode spot and consist of pure cathode material. The main drawbacks with droplets are their negative impact on both the surface roughness and the interruption of the coating growth. An example of a droplet in a coating is shown in Figure 7 where the disturbance of the growth is exemplified. Large voids beneath the droplet are also occurring which have their origin in a shadowing effect [71].

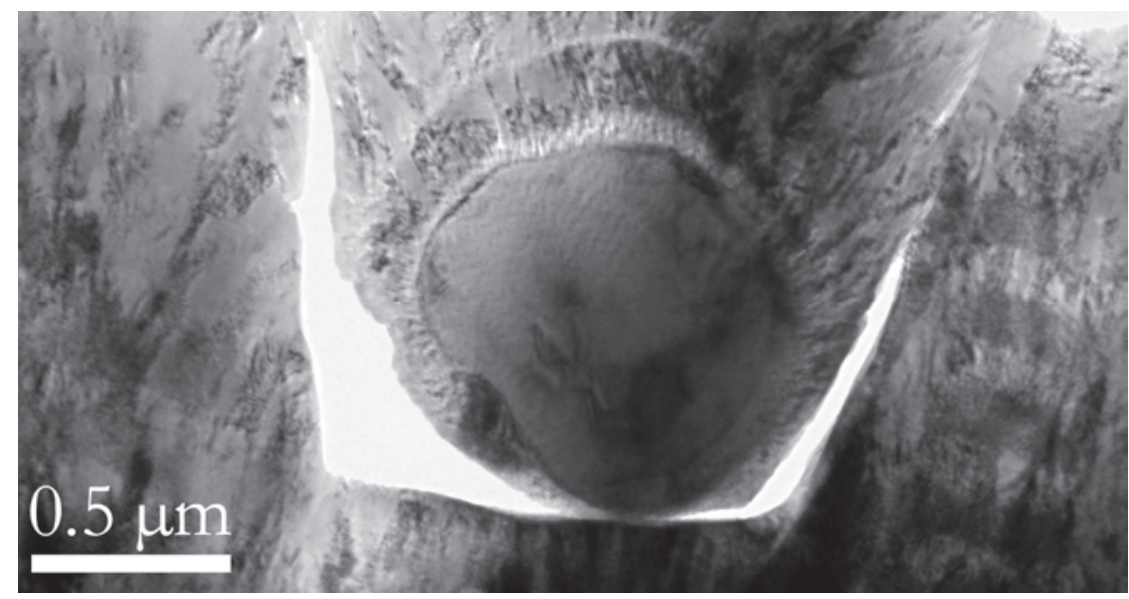

Figure 7. Transmission electron micrograph showing a droplet in an as-deposited $\mathrm{Ti}_{0.50} \mathrm{Al}_{0.50} \mathrm{~N}$ coating. The bright areas beneath the droplet are voids due to shadowing effects from the droplet.

Since the droplets consist of pure metal from the cathode, the mechanical properties in the droplets are generally lower compared to the coating. This is exemplified in Figure 8 where nanoindentation has been used to generate a hardness map of a heat treated $\mathrm{Ti}_{0.33} \mathrm{Al}_{0.67} \mathrm{~N}$ coating. The dark areas are droplet positions with a hardness around $20 \mathrm{GPa}$ which is considerable lower 
compared to the surrounding $\operatorname{Ti}_{0.33} \mathrm{Al}_{0.67} \mathrm{~N}$ with hardness values above $30 \mathrm{GPa}$. In order to avoid measuring the droplets, and also to improve the surface roughness, the samples used in nanoindentation are therefore tapered and polished. An optical microscope is then used to manually select areas free of droplets.

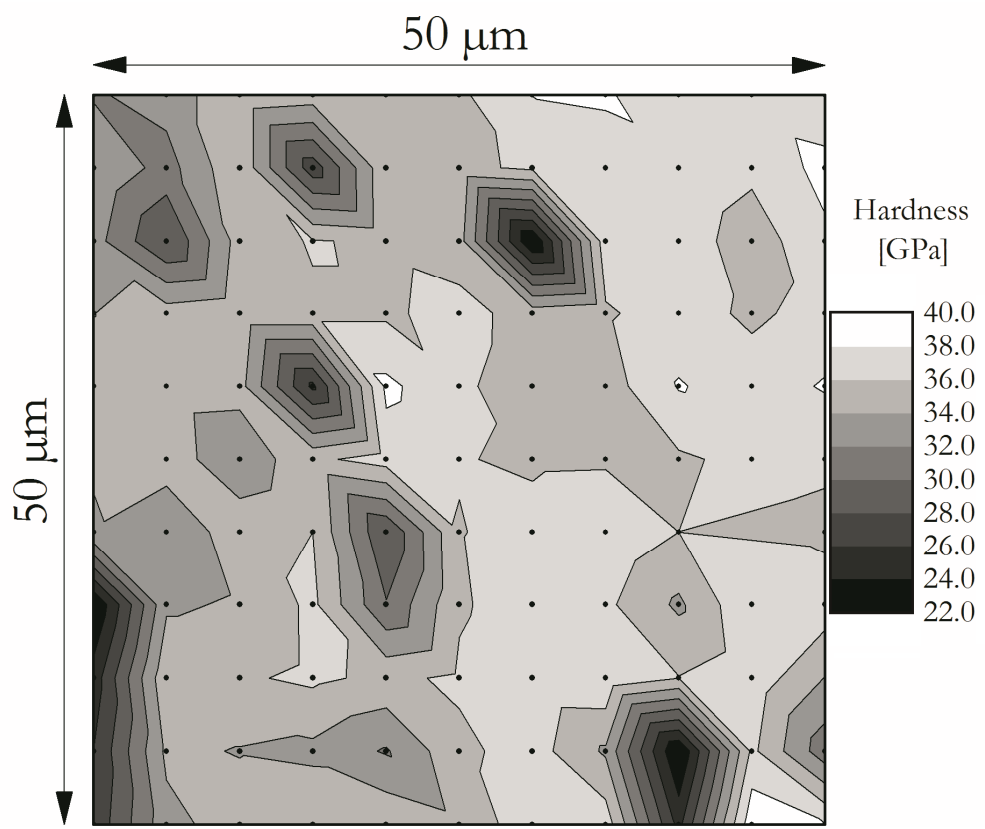

Figure 8. A hardness map with $5 \mu \mathrm{m}$ resolution, the indents are marked in the figure with dots. The dark areas have been measured at droplet positions.

Several methods to minimize the droplet density exist, where the most common ones include the use of magnetic filters [72,73]. The filters work by directing the charged species in the plasma, for example with a $90^{\circ}$ duct filter from the cathode to the substrate. Since the droplets are heavy with no net charge, their trajectories are not affected by the filters. The filters are however not common in the cutting tool industry as there is a severe reduction in deposition rate not compensated by the improvement of the hard coatings. 



\section{CHAPTER 4}

The ceramic compound TiN was one of the first material systems for hard coatings on cutting inserts, motivated by its enhanced machining properties compared to uncoated tools [74]. The crystal structure of TiN is the cubic $\mathrm{NaCl}$ (B1, c-TiN) structure shown in Figure 9 (a). Aluminum was in the late 1980s [1,2] added to the system as a first intent to improve the oxidation resistance of TiN. The equilibrium crystal structure of AIN at ambient conditions is the hexagonal wurtzite structure (B4, h-AlN), Figure 9 (b). Thermodynamically, h-AlN is soluble into TiN with only a few atomic percent [75] but the low deposition temperature during cathodic arc evaporation instead enables the growth of c-TiAlN up to an aluminum content around $70 \%$ [12]. The structure of c-TiAlN is identical to c-TiN with $\mathrm{Al}$ atoms distributed randomly at Ti sites in the lattice.
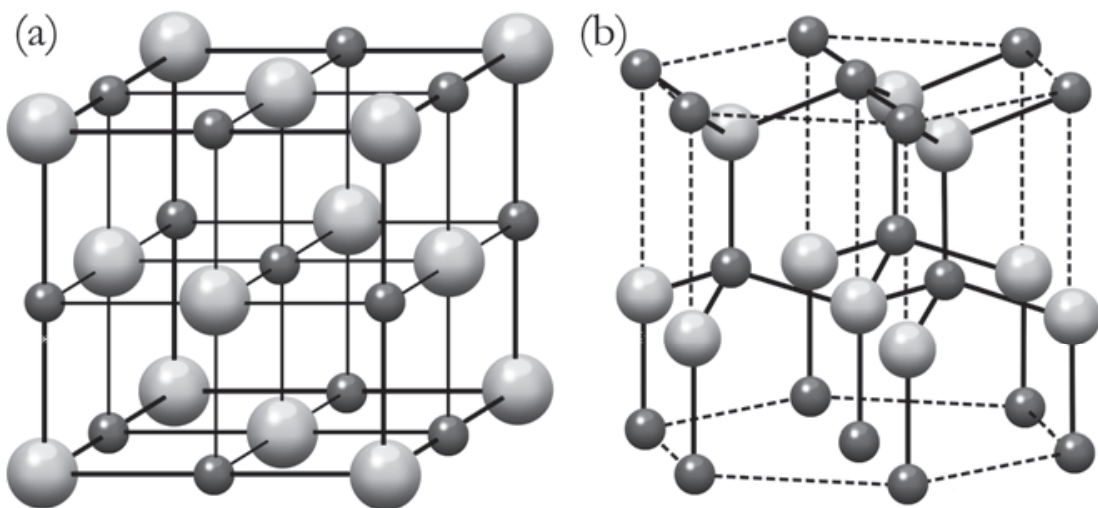

Figure 9. (a) B1, $\mathrm{NaCl}$ and (b) B4, wurtzite crystal structures. The larger spheres correspond to Ti or $\mathrm{Al}$ and the smaller to $\mathrm{N}$. 
At elevated temperatures, the unstable c-TiAlN decomposes in two steps. The first step involves a spinodal decomposition into c-TiN and c-AlN rich domains which is followed by nucleation and growth of c-AlN into h-AlN. The following chapter introduces results from this thesis during the decomposition steps, see Chapter 5 for details about the characterization methods.

\subsection{Spinodal decomposition of TIAIN}

In the non-equilibrium phase diagram, a miscibility gap with a negative second derivative of Gibbs free energy [76] is observed between c-AlN and c-TiN. Due to this, the isostructural decomposition has been shown to be a spinodal type where the decomposed c-TiN and c-AlN rich domains are coherent and have a domain size (spinodal wavelength) in the nanometer region $[6-11,77]$. Although there is, by definition, no energy barrier associated with the spinodal decomposition, an increased temperature is required for diffusional processes to occur. The spinodal decomposition during heating with $20^{\circ} \mathrm{C} / \mathrm{min}$ (black lines) and up to $40 \mathrm{~min}$ of isothermal annealing at $1000{ }^{\circ} \mathrm{C}$ (gray lines) for $\mathrm{Ti}_{0.36} \mathrm{Al}_{0.64} \mathrm{~N}$ can be seen in the x-ray diffractograms in Figure 10.

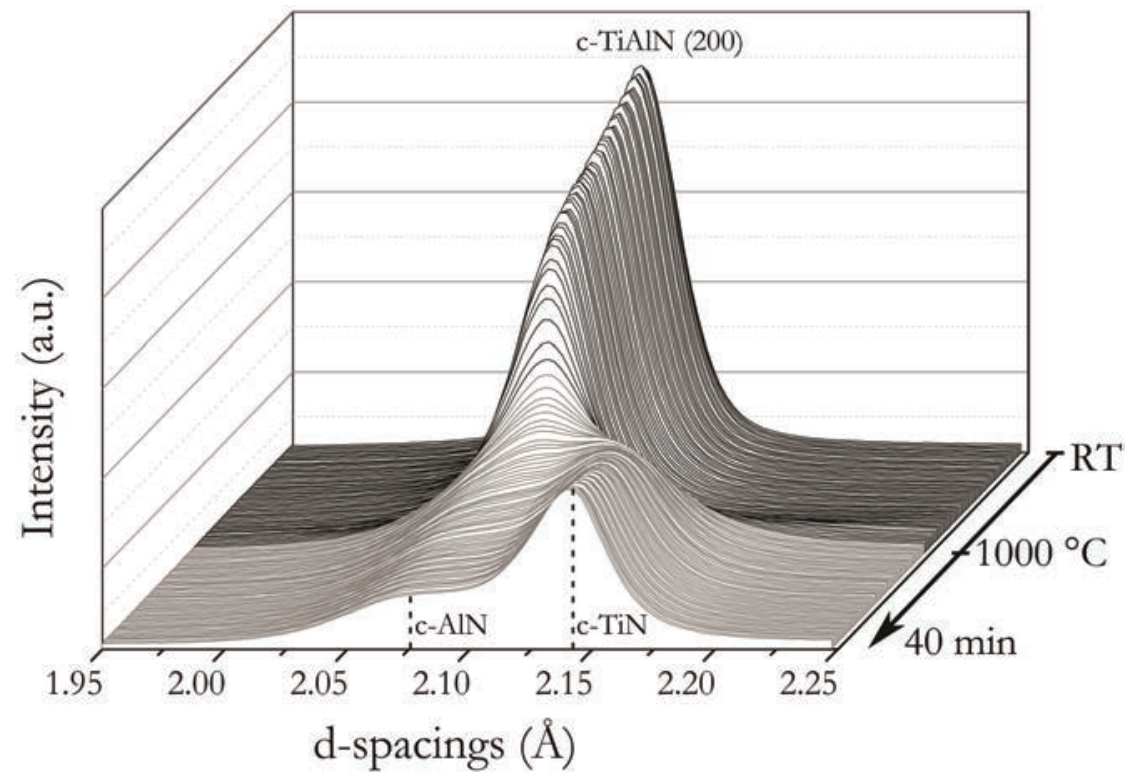

Figure 10. In-situ x-ray diffractograms as a function of temperature and isothermal annealing time at $1000{ }^{\circ} \mathrm{C}$. The black lines correspond to heating and the gray lines to isothermal annealing. The markers for c-AlN and c-TiN are approximate at the temperature of $1000^{\circ} \mathrm{C}$. 
During the initial stage of the decomposition, there is a broadening of the c-TiAlN peak due to the gradual segregation of the coherent c-TiN and c-AlN rich domains. The coherent domains give rise to an increase in hardness because of an effective hindering of dislocation motion induced by the coherency strain between the domains [78], as is described in section 2.2.1 Precipitation hardening. With further annealing, the broadening of the peak evolves into two separate peaks corresponding to pure c-AlN and c-TiN. After this, the domains coarsen in order to minimize the gradient energy.

The evolution of the spinodal wavelength during the decomposition can be studied with small angle $\mathrm{x}$-ray scattering. This is shown in Figure 11 during a continuous temperature increase $\left(20{ }^{\circ} \mathrm{C} / \mathrm{min}\right)$ for (a) $\mathrm{Ti}_{0.36} \mathrm{Al}_{0.64} \mathrm{~N}$ and (b) $\mathrm{Ti}_{0.55} \mathrm{Al}_{0.45} \mathrm{~N}$ up to two different temperatures for each composition. The first sign of the decomposition is seen around $700{ }^{\circ} \mathrm{C}$ for both compositions with a corresponding spinodal wavelength of $\sim 2.5 \mathrm{~nm}$. With increasing temperature, the wavelength increases exponentially during the subsequent coarsening stage. Eventually, the c-AlN domains grow large enough to initiate the nucleation and growth of h-AlN, which is further described later.
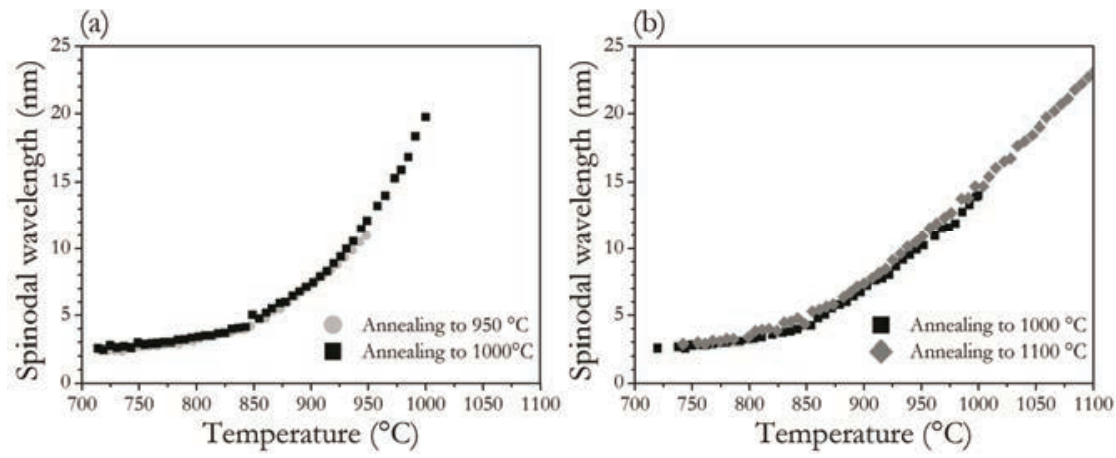

Figure 11. Spinodal wavelength as a function of isochronal annealing temperature for (a) $\mathrm{Ti}_{0.36} \mathrm{Al}_{0.64} \mathrm{~N}$ and (b) $\mathrm{Ti}_{0.55} \mathrm{Al}_{0.45} \mathrm{~N}$. Two separate measurement runs have been executed for each composition with different end temperatures. From Paper $V$. 


\subsubsection{Anisotropic effects on the mic rostructure}

Zener's anisotropy factor, $A_{z}$, [79] which is defined in Eq. (7) below determines the elastically softer directions, where $\mathrm{A}_{\mathrm{z}}<1$ corresponds to $\mathrm{E}_{111}<\mathrm{E}_{100}$ and $\mathrm{A}_{\mathrm{z}}>1$ to $\mathrm{E}_{111}>\mathrm{E}_{100}$.

$A_{z}=\frac{2 C_{44}}{C_{11}-C_{12}}$

where $C_{i j}$ are the independent elastic stiffness constants in a cubic system. The effect of the anisotropy on the spinodal decomposition was shown analytically in a paper by Cahn [35]. During spinodal decomposition, there is an increase in elastic energy due to the coherent domains as they exhibit differences in elastic constants and lattice parameters. Thus, the initial microstructure of spinodal decomposition is highly influenced by the system's ability to minimize the elastic energy. For systems with an elastic anisotropy, the direction of the concentration waves during spinodal decomposition will be along the elastically softer directions. A majority of metals have $A_{z}>1$ and thus a microstructure consisting of concentration waves in the $<100>$ directions are most common after spinodal decomposition, see for example Baker et al. [80].

The ab initio calculated elastic constants in combination with experimental data in the $\mathrm{Ti}_{1-\mathrm{x}} \mathrm{Al}_{\mathrm{x}} \mathrm{N}$ system [78] show a Zener anisotropy which is highly composition dependent. According to the authors [78], $\mathrm{Ti}_{1_{-\mathrm{x}}} \mathrm{Al}_{\mathrm{x}} \mathrm{N}$ is isotropic $\left(A_{z}=1\right)$ at $x=0.28$ with $A_{z}<1$ for $x<0.28$ and $A_{z}>1$ for $x>0.28$. Thus, the evolving microstructure during spinodal decomposition should be periodically aligned in the elastically softer $\langle 100\rangle$ directions with $\mathrm{Al}$ composition greater than 0.28. This was experimentally shown in Paper III and an example of this is also seen in Figure 12 which shows STEM and HRTEM micrographs at a [002] zone axis.

In Paper III, TEM results after annealing of $\mathrm{Ti}_{0.69} \mathrm{Al}_{0.31} \mathrm{~N}$, i.e., close to the isotropic limit, also demonstrated a microstructure consisting of randomly ordered domains. The differences in microstructure between the different compositions were shown to affect the hardness of the coating. In $\mathrm{Ti}_{0.69} \mathrm{Al}_{0.31} \mathrm{~N}$, the age hardening effect was completely lost but most pronounced in the high $\mathrm{Al}$ content coating. Sonderegger et al. [81] discussed the strengthening effect of particles with different shapes and deviations from spherical domains to oblate or prolate shapes. Since spherical domains demonstrate the longest distance between domains, oblate or prolate shaped particles exhibited an increased hardness of the material, i.e., very similar to what was observed for TiAlN in Paper III. 


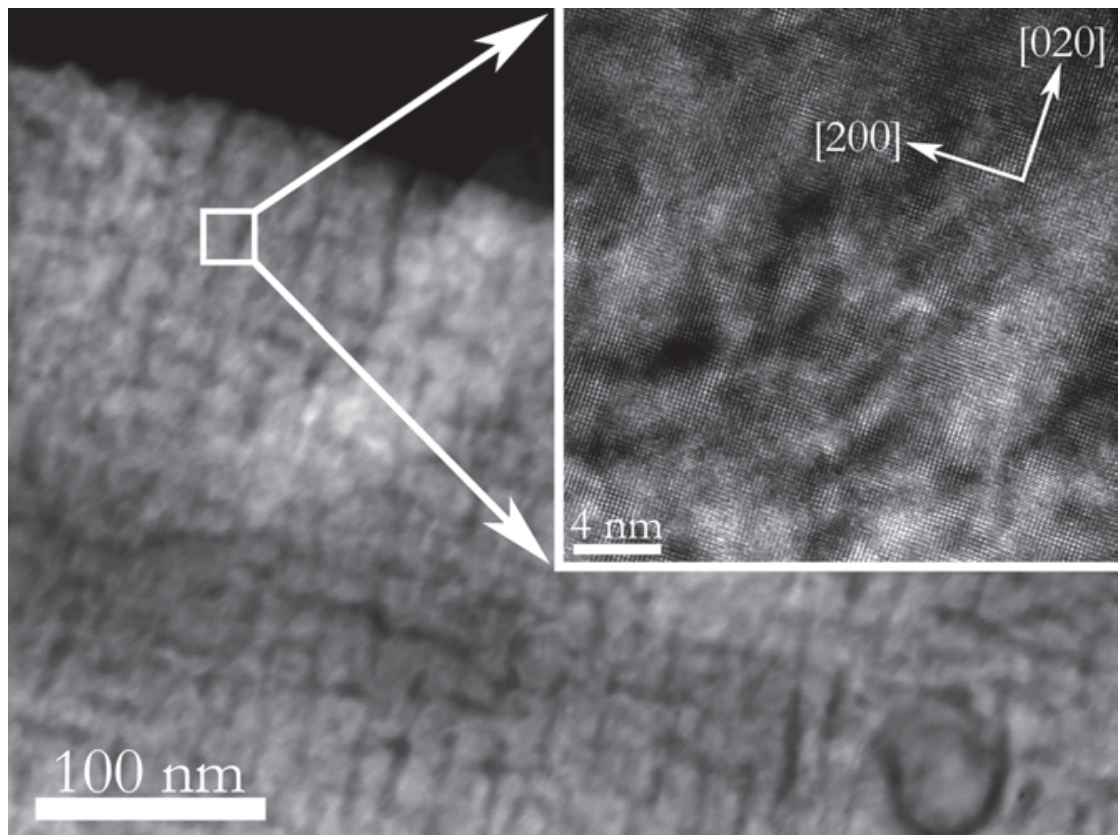

Figure 12. STEM with HRTEM (inset) micrograph showing the anisotropic microstructure during the spinodal decomposition.

\subsection{Nucleation and growth of h-AIN}

At ambient pressures, the coarsening of the c-AlN domains leads to a critical wavelength before nucleation of h-AlN [5] which was measured to around $13 \mathrm{~nm}$ in Paper $V$ by using a combination of WAXS and SAXS. In addition, the kinetics of the transformation in TiAlN powder was studied in Paper $V$ with in-situ synchrotron $\mathrm{x}$-ray scattering. The fraction of c-AlN transformed into h-AlN with different isothermal annealing is shown in Figure 13 for (a) $\mathrm{Ti}_{0.36} \mathrm{Al}_{0.64} \mathrm{~N}$ and (b) $\mathrm{Ti}_{0.55} \mathrm{Al}_{0.45} \mathrm{~N}$ and the results show a strong increase in the transformation rate with the increase in $\mathrm{Al}$ content. This is exemplified by the almost identical curves for $\mathrm{Ti}_{0.36} \mathrm{Al}_{0.64} \mathrm{~N}$ at $1000{ }^{\circ} \mathrm{C}$ and $\mathrm{Ti}_{0.55} \mathrm{Al}_{0.45} \mathrm{~N}$ at $1100{ }^{\circ} \mathrm{C}$, i.e., a temperature increase of $100{ }^{\circ} \mathrm{C}$ is required to obtain a transformation rate in $\mathrm{Ti}_{0.55} \mathrm{Al}_{0.45} \mathrm{~N}$ comparable with $\mathrm{Ti}_{0.36} \mathrm{Al}_{0.64} \mathrm{~N}$. The onset of the nucleation is also composition dependent, with $950{ }^{\circ} \mathrm{C}$ for $\operatorname{Ti}_{0.36} \mathrm{Al}_{0.64} \mathrm{~N}$ and $1000{ }^{\circ} \mathrm{C}$ for $\mathrm{Ti}_{0.55} \mathrm{Al}_{0.45} \mathrm{~N}$ during heating with $20^{\circ} \mathrm{C} / \mathrm{min}$.

The modified KJMA equation, Eq. (5), was used to calculate the associated activation energies. Despite the large differences in transformation rate, the activation energy was similar for both compositions with $320 \pm 10 \mathrm{~kJ} / \mathrm{mol}$ for $\operatorname{Ti}_{0.36} \mathrm{Al}_{0.64} \mathrm{~N}$ and $350 \pm 40 \mathrm{~kJ} / \mathrm{mol}$ for $\operatorname{Ti}_{0.55} \mathrm{Al}_{0.45} \mathrm{~N}$. The reason is the similarities in $\mathrm{Al}$ content in the domains where h-AlN is nucleated, due to the 
precedent spinodal decomposition and coarsening. The deviation in transformation rate for the different compositions is consequently a combination of the obtained anisotropic microstructure during spinodal decomposition and the stabilization of c-AlN induced by the presence of c-TiN.

(a)

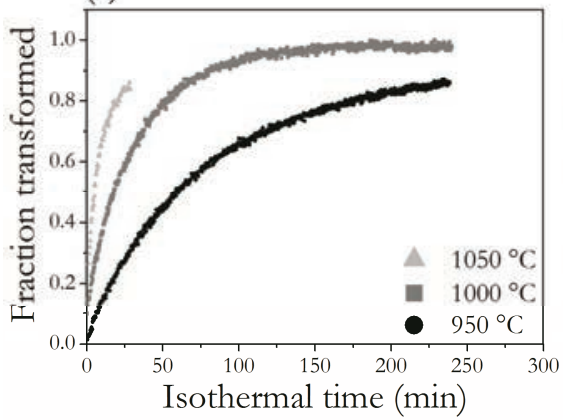

(b)

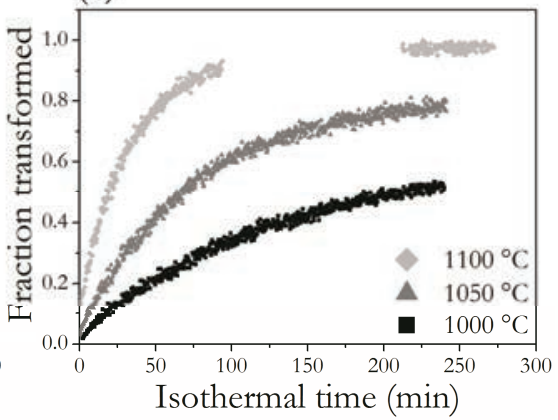

Figure 13. Fraction of c-AlN transformed into h-AlN as a function of isothermal temperature for (a) $\mathrm{Ti}_{0.36} \mathrm{Al}_{0.64} \mathrm{~N}$ and (b) $\mathrm{Ti}_{0.55} \mathrm{Al}_{0.45} \mathrm{~N}$. From Paper $V$.

\subsection{The influence of pressure}

The thermal stability of TiAlN, and how it is affected by, e.g., alloying with additional elements [82-91] or multilayer structures [8,57] is well studied in the literature. During a typical metal cutting operation however, large cutting forces ( $\mathrm{kN}$ regime) prevail in combination with elevated temperatures. As is seen in Chapter 7, the combination of large cutting forces and the small contact area $\left(\mathrm{mm}^{2}\right.$ regime) yields an applied pressure of several GPa on the coating. The effect of pressure on the phase stability of TiAlN has been described theoretically by Alling et al. [92] and Holec et al. [93].

Holec et al. calculated the maximum solubility of $\mathrm{AlN}$ in $\mathrm{Ti}_{1_{-\mathrm{x}}} \mathrm{Al}_{\mathrm{x}} \mathrm{N}$ while maintaining the cubic structure and showed a gradual increase in solubility with the applied pressure. At a pressure of $4 \mathrm{GPa}$, the solubility limit increased from $x=0.70$ to $x=0.78$, i.e., an increase of $11 \%$. Thus, the compressive bi-axial stresses during coating growth is likely a contributing factor for an increased $\mathrm{Al}$ content in cubic $\mathrm{Ti}_{1-\mathrm{x}} \mathrm{Al}_{\mathrm{x}} \mathrm{N}$ coatings while maintaining the cubic structure.

Alling et al. showed a promoting effect of pressure on the spinodal composition in combination with a stabilization of c-AlN over h-AlN. Due to asymmetry in the isostructural phase diagram, the pressure effect on the spinodal decomposition was shown to be largest at compositions around $\mathrm{x}=0.40$. Both the promoted spinodal decomposition and the suppressed transformation to h-AlN were explained by the fundamental thermodynamic 
equation in Eq. (8) which describes the pressure derivative of Gibbs free energy $(G)$ at a given temperature.

$\left(\frac{\partial \Delta G}{\partial P}\right)_{T}=\Delta V$

where $\mathrm{V}$ is the volume, $\mathrm{P}$ the pressure and $\Delta$ the change according to Eq. (9):

$$
\begin{aligned}
& \Delta M=M_{T i_{1-x} A l_{x} N}-(1-x) M_{T i N}-x M_{A l N} \\
& (M=G, V)
\end{aligned}
$$

$\Delta \mathrm{V}$ is thus the deviation from Vegard's behavior which shows a linear dependence of the volume with respect to the composition of the components [94]. This deviation has earlier been shown to be positive for the isostructural case both experimentally [95] and theoretically [96]. Conversely, $\Delta \mathrm{V}$ is negative for the cubic to hexagonal transformation due to the $\sim 20 \%$ larger volume of h-AIN compared to c-AlN [6]. Both of these pressure effects were observed experimentally in Paper I and Paper II.

In Paper I, the spinodal wavelengths after metal cutting and heat treatments were compared. Despite comparable times and temperatures, an overall increased wavelength was observed after metal cutting which was attributed to the applied pressure during metal cutting. A different approach was used in Paper II where high pressure instruments (described in Chapter 6) were used to reach quasi-hydrostatic pressures up to $23 \mathrm{GPa}$ in combination with elevated temperatures up to $2200{ }^{\circ} \mathrm{C}$. The samples were mainly analyzed ex-situ with $\mathrm{x}$-ray diffraction. In combination with the experimental study, first-principles calculations were employed to obtain a theoretical phase diagram for pure AlN. The phase diagram, together with experimental data points, is shown in Figure 14 where the solid line shows the theoretical equilibrium line between $\mathrm{c}-\mathrm{AlN}$ and $\mathrm{h}$-AlN. The hexagons indicate the experimental samples where presence of h-AlN was observed and the squares where evidence of spinodal decomposition was detected. 


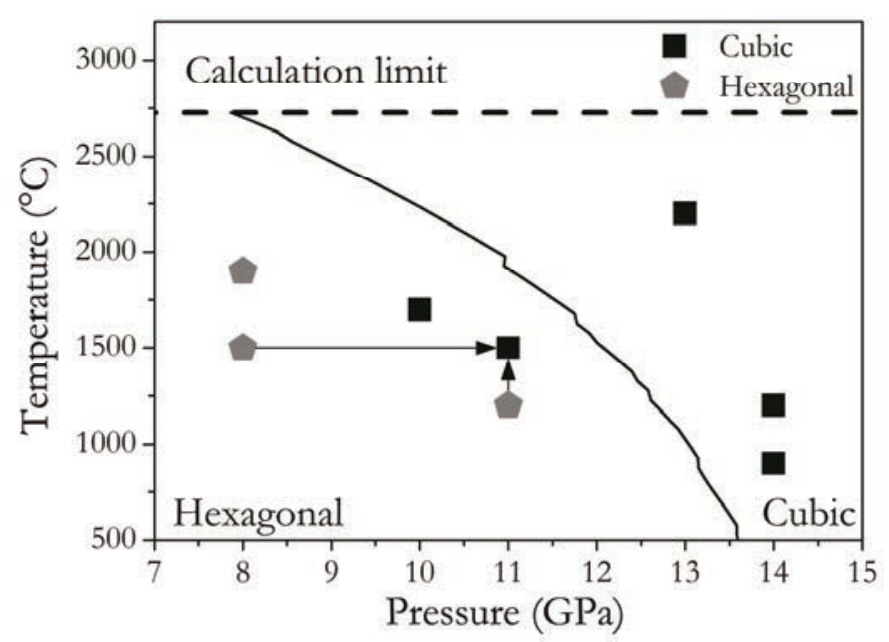

Figure 14. Phase diagram showing the stability regions of AlN at different temperatures and pressures. The data points show experimental values obtained for TiAlN. The arrows note the stabilization of c-AlN over h-AlN regarding both an increased pressure and an increased temperature. From Paper II.

The calculated phase diagram is consistent with previous theoretical and experimental studies performed on pure AlN [97-100]. The negative curvature of the equilibrium line indicates a stabilization of c-AlN over h-AlN with both an increased pressure and by an increased temperature at elevated pressures. Both these trends are validated for $\mathrm{Ti}_{0.60} \mathrm{Al}_{0.40} \mathrm{~N}$ by the experimental data as is indicated by the arrows. As the experimental data is valid for $\mathrm{Ti}_{0.60} \mathrm{Al}_{0.40} \mathrm{~N}$ and the calculated phase diagram for $\mathrm{AlN}$ the lack of hexagonal phase at $11 \mathrm{GPa} / 1500{ }^{\circ} \mathrm{C}$ and $10 \mathrm{GPa} / 1700{ }^{\circ} \mathrm{C}$ suggests a further stabilization of c-AlN with the addition of TiN. This could be explained by a template effect where the domains of c-AlN are surrounded by coherent domains of c-TiN. 


\section{Characterization methods}

Characterization techniques include methods to study the structural, chemical, mechanical and thermal properties in the materials. In this work, all of these material properties have been studied with a variety of experimental setups described below.

\subsection{X-ray diffraction}

$\mathrm{X}$-ray diffraction (XRD) is a well-established characterization technique for coating materials, mainly due to its ability to characterize, e.g., phases or internal and external stresses in the samples. In addition, XRD is also a non-destructive technique with little or none sample preparation. XRD is often divided into two main techniques, wide angle $\mathrm{x}$-ray scattering (WAXS) and small angle x-ray scattering (SAXS), both of them described in detail on the following pages.

\subsubsection{Wide angle x-ray scattering}

As the $\mathrm{x}$-ray wavelengths are in the same order as the atomic distances in materials, the scattering of $\mathrm{x}$-rays by the core electrons gives rise to constructive and destructive interference according to the superposition principle. The conditions for constructive interference are described by Bragg's law, shown in Eq. (10) below.

$n \lambda=2 d \cdot \sin \theta$

where $\mathrm{n}$ is an integer, $\lambda$ the $\mathrm{x}$-ray wavelength, $\mathrm{d}$ the distance between adjacent parallel planes and $\theta$ half the scattering angle. Bragg's law is though only a first condition for constructive interference to occur since some scattering planes in crystal structures (with a few exceptions such as the simple cubic structure) will interfere destructively despite being fulfilled by 
Bragg's law. This is solved by combining Bragg's law with the structure factor for the specific crystal structure. By doing this for an fcc lattice, it can be determined that the only planes that allow constructive interference is those where $h, k$ and $l$ are either all even or all odd. Hence, constructive diffraction from $\{100\}$ planes does not occur but instead from $\{200\}$ planes. Another method is to first construct the reciprocal lattice vector $\mathbf{G}$ according to Eq. (11) and Eq. (12):

$\boldsymbol{G}=\sum_{1}^{3} \boldsymbol{b}_{\boldsymbol{i}} \cdot n_{i} \quad \mathrm{n}_{\mathrm{i}}=\mathrm{h}, \mathrm{k}$ and $\mathrm{l}$

$\boldsymbol{b}_{1}=\frac{2 \pi\left(\boldsymbol{a}_{2} \times \boldsymbol{a}_{3}\right)}{\left|\boldsymbol{a}_{\mathbf{1}} \times \boldsymbol{a}_{\mathbf{2}} \cdot \boldsymbol{a}_{3}\right|} \quad$ (cyclic permutation)

where $\mathbf{b}$ is the reciprocal primitive basis vectors and $\mathbf{a}$ the real space equivalent. Constructive interference then occurs when $\mathbf{G}$ is equal to the difference $(\Delta \mathbf{k})$ between the scattered wave vector $\mathbf{k}^{\prime}$ and incident wave vector $\mathbf{k}$. Using this method, the structure factor is not necessary to evaluate since only reflections from allowed hkl planes are included in the reciprocal lattice.

The most common XRD setup is the Bragg-Brentano geometry (reflective mode), where the detector is scanned symmetrically with the incident $\mathrm{x}$-ray, see Figure 6 for an example of such a diffractogram. Due to this symmetry, $\Delta \mathbf{k}$ is always perpendicular to the surface and the only detectable planes are parallel with the surface. This is used to calculate $T_{C}$ in Eq. (6) as the difference between the actual XRD spectrum and a powder spectrum gives information about the preferred orientation in the growth direction (GD). This does however not give a complete picture of the texture as only a subset of the grains is measured. To solve this, a diffractometer with full rotational freedom is needed, often called an Euler cradle. This setup enables the possibility to select a specific plane spacing and measure the intensity while rotating the sample according to Figure 15. 


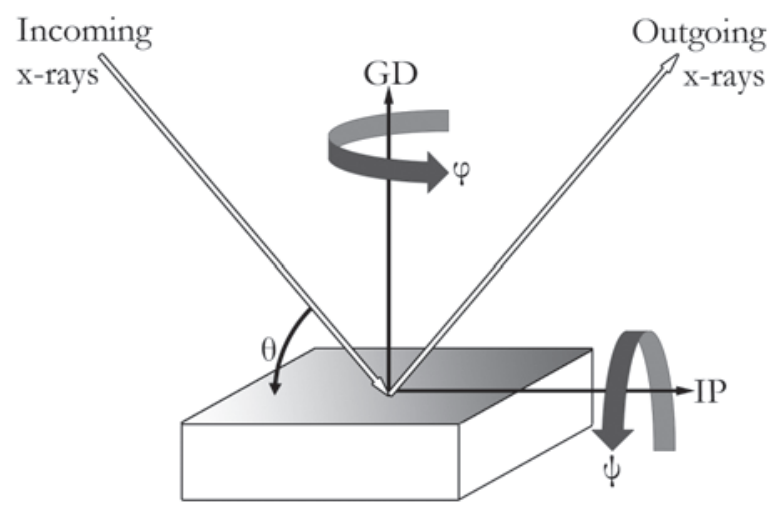

Figure 15. Schematic setup of an Euler cradle.

During the measurement, the Bragg angle $\theta$ is fixed while completing a rotation along the growth direction $(\varphi)$ and in-plane direction (IP, $\psi$ ). The intensity is commonly projected on two-dimensional pole figures which were used in Paper $I V$ to investigate the preferred orientation in different configurations of $\mathrm{Ti}_{0.50} \mathrm{Al}_{0.50} \mathrm{~N}$. The Euler cradle can also be used to measure the stress state of the coatings with the $\sin ^{2} \psi$ method [101]. In the method, the plane spacing, $d_{\psi}$, is measured at different values of $\psi$ and by assuming a bi-axial stress state (where the out-of-plane stress is zero) the strain, $\varepsilon_{\psi}$, in the coating is approximated to:

$\varepsilon_{\psi}=\frac{d_{\psi}-d_{0}}{d_{0}}=\frac{1+v_{h k l}}{E_{h k l}} \sigma \sin ^{2} \psi-\frac{2 v_{h k l}}{E_{h k l}} \sigma$

where $d_{0}$ is the strain-free lattice spacing, Vhkl the Poisson's ratio, Ehkl the elastic modulus and $\sigma$ the in-plane stress. Rearranging, the linear dependence of $d_{\psi}$ on $\sin ^{2} \psi$ is realized:

$d_{\psi}=d_{0}\left(\frac{1+v_{h k l}}{E_{h k l}} \sigma \sin ^{2} \psi-\frac{2 v_{h k l}}{E_{h k l}} \sigma\right)+d_{0}$

Thus, the slope of a $d_{\psi}-\sin ^{2} \psi$ plot determines the in-plane stress with knowledge of the elastic constants and strain-free lattice spacing. With increasing Bragg angle, the shift in lattice peak positions increases and thus the accuracy of the measurement. High indices lattice plane reflections are thus preferred but not always accessible due to preferred orientations. If deviations from the assumed bi-axial stress state are present, for example with a stress gradient in growth direction, the $d_{\psi}-\sin ^{2} \psi$ plot will show an oscillatory behavior. 
In Paper II and Paper $V$, the XRD measurements were performed in transmitting mode with a two-dimensional detector on powder samples. In Paper II, a high brilliance in-house diffractometer was used whereas a synchrotron source was used in Paper $V$. When measuring on a powder, there is no possibility to obtain texture information and the diffraction instead gives rise to rings, which is seen in Figure 16 (a). The radii of the rings are proportional to the scattering angle, hence inversely proportional to the d-spacings. The d-spacings are calculated with the sample-to-detector distance and wavelength of the radiation, where after lineouts are calculated from the two-dimensional spectrum by a radial integration, as is seen in Figure 16 (b).

In the example, the (111), (200) and (220) reflections of as-deposited $\mathrm{Ti}_{0.36} \mathrm{Al}_{0.64} \mathrm{~N}$ are shown. The broad peaks are mainly due to small crystal grains and microstrain in the sample, in combination with a small instrumental broadening from the diffractometer. During data analysis, the peaks are fitted with a pseudo-Voigt function after which peak position, peak width and integrated peak intensity can be measured.
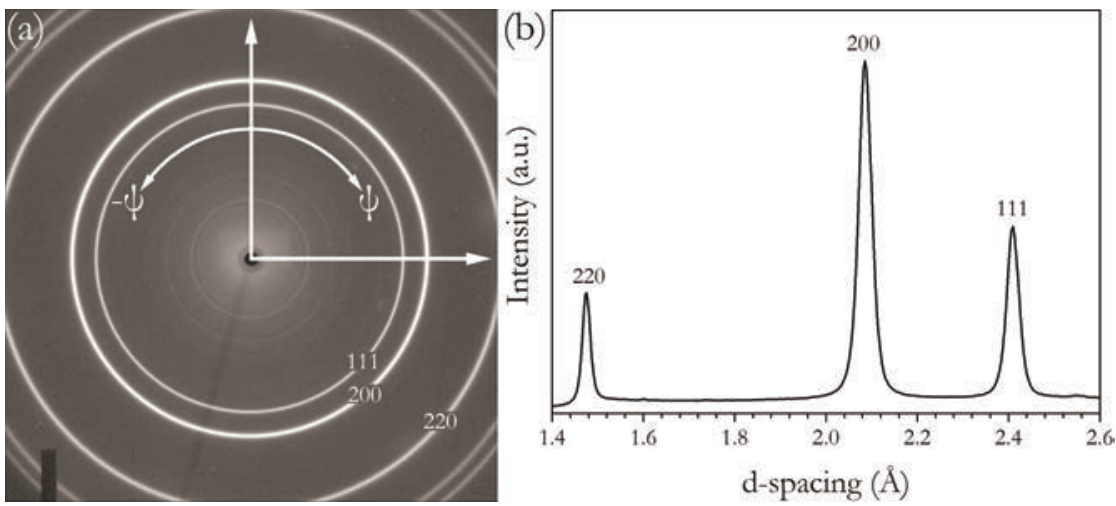

Figure 16. (a) Raw data from the 2D PerkinElmer detector used during synchrotron measurements and (b) a radial integration of the rings in (a).

\subsubsection{Small angle $x$-ray scattering}

If nanometer sized domains with different electron densities are present in a material, small angle $\mathrm{x}$-ray scattering (SAXS) can be used to measure their sizes. The principle is identical to wide angle $\mathrm{x}$-ray scattering but with angles of $0-1^{\circ}$ instead of $>20^{\circ}$. SAXS was used in Paper $V$ to measure the wavelength evolution of the c-TiN and c-AlN rich domains with temperature during the spinodal decomposition and coarsening.

The scattering from the domains during spinodal decomposition results in a diffuse ring around the beam stop with a radius that decreases as the the domains grow. Following an identical procedure as in WAXS, lineouts are 
produced from the two-dimensional spectrums for each measurement. The lineouts show the scattered intensity as a function of the scattering vector, q, which is defined as

$q=\frac{4 \pi}{\lambda} \sin \theta$

where $\lambda$ is the $\mathrm{x}$-ray wavelength and $\theta$ the scattering angle. An example during continuous heating of $\mathrm{Ti}_{0.36} \mathrm{Al}_{0.64} \mathrm{~N}$ is seen in Figure 17 for four different temperatures. The intensity drop seen at q-values below $0.02 \AA^{-1}$ (dashed line) are a result of the beam stop. A SAXS pattern can be divided into two different key features, the Porod region and the Guinier region. The information about the size and shape is present in the Guinier region [102] which is indicated by arrows in Figure 17 for the different temperatures. At $400{ }^{\circ} \mathrm{C}$, the spinodal decomposition has not started as this temperature is lower than the deposition temperature and hence no SAXS peak is visible.

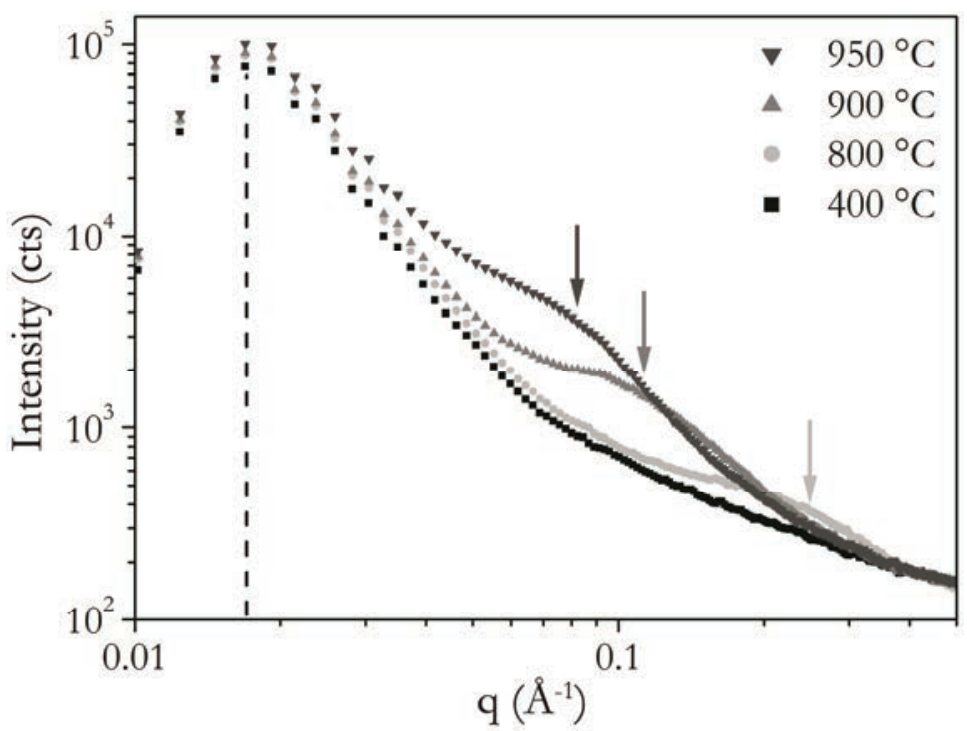

Figure 17. Intensity as a function of q-values at different temperatures. The SAXS signal occurs at smaller q-values with increasing temperature, indicating a coarsening of the domains after spinodal decomposition. 
In this work, the Guinier region in the data was evaluated with the Unified fit [103] method in the Irena Package for Igor Pro [104]. The fitting procedure results in the radius of gyration, $R_{G}$, for the domains which with knowledge of the scattering object's shape provides the size information. By assuming spherical domains $\left(\mathrm{R}=1.29 \mathrm{R}_{\mathrm{G}}\right)$ [105] and multiplying the radius with four, the wavelength evolution with annealing temperature shown in Figure 11 is calculated. Although the assumption of spherical domains is not entirely correct, TEM analyzes in previous works $[11,106]$ indicate only minor errors.

\subsection{Electron mic rosc opy}

According to the wave-particle duality, all particles can be described as waves with a de Broglie wavelength. Considering relativistic effects, an electron accelerated to $100 \mathrm{keV}$ have a wavelength of roughly $4 \mathrm{pm}$ [107]. This affects the resolution in a microscope, which is determined by the Rayleigh criterion, where there is a linear dependence between the resolution and the wavelength. Since the wavelength used in light optical microscopes is around $500 \mathrm{~nm}$, the resolution is several magnitudes better in an electron microscope. However, the lenses used in an electron microscope are electromagnetic, as compared to the glass lenses in a light optical microscope. This severely lowers the practical resolution compared to the theoretical one, e.g., due to aberration and astigmatism in the electromagnetic lenses. With the development of aberration correctors [108,109] and monochromators [110] the resolution in modern transmission electron microscopes is improved to sub-angstrom levels. In this work, electron microscopes in scanning and transmission mode have been used, both of them described in the following pages.

\subsubsection{Scanning electron mic rosc opy}

In a scanning electron microscope (SEM), an electron probe is scanned on the surface of the sample to be examined. The electron energy is usually varied between a few and several tens of $\mathrm{keV}$. With larger electron energies, the resolution is improved to the expense of a reduced surface sensitivity due to an increased interaction volume within the sample. Compared to a transmission electron microscope, described below, the resolution is also lower in a SEM due to the lower electron energies. However, because of the ease of use, simple sample preparation and straightforward interpretation of the micrographs, the SEM is frequently used in materials science.

During interaction of the electrons with the sample, secondary electrons, backscattered electrons and x-rays are generated. The secondary electrons are caused by the ionization of the sample and characterized by a low kinetic energy with an origin close to the surface. Thus, due to shadowing effects, the 
detection of secondary electrons gives a topographic contrast. The backscattered electrons are elastically scattered primary electrons with a higher energy than that of the secondary electrons. Since the scattering is more dominant for heavier elements, the contrast mechanism from backscattered electrons is mainly atomic mass number $(\mathrm{Z})$ contrast.

\subsubsection{Transmission electron mic rosc opy}

In transmission electron microscopy (TEM), an acceleration voltage of several hundred $\mathrm{kV}$ is used. The higher electron energy improves the resolution compared to SEM and with thin samples $(<100 \mathrm{~nm})$ the electrons are transmitted through the sample. Although TEM requires a tedious sample preparation and the probed volume is very small, it is widely used for analysis of coatings. Its multifaceted use gives information about the microstructure (including defects and interfaces), crystal structure and chemical composition (including elements and bindings).

The electrons are emitted from an electron gun after which they are accelerated by a potential difference. Before and after the sample, electromagnetic lenses focus the electrons in the TEM column. After transmission through the sample, the electrons are focused on a fluorescent screen or a CCD camera where an image is formed. During interaction with the sample, the electrons are transmitted, absorbed or scattered which governs the contrast mechanisms in a TEM.

In bright field mode, shown in Figure 18 (a), the strongest contrast mechanisms are mass/thickness and diffraction contrast. Mass/thickness contrast is present as thicker regions or heavier elements in the sample absorb or scatter a larger amount of electrons. Consequently, thicker regions or regions with heavy elements appear darker in the micrograph. Diffraction in the sample also occurs due to the periodicity of the crystals. Thus, by introducing an objective aperture it is possible to block the diffracted electrons so grains oriented with a high symmetry crystal orientation parallel to the electron beam will appear dark. Defect densities in the sample also diffract electrons due to the local variations in strain which provides the possibility to image dislocations and defects.

The objective aperture can also be removed from the central beam in the diffraction plane and only transmit electrons diffracted from a specific or several chosen crystallographic orientations. This is called dark field mode and is shown in Figure 18 (b). Both bright and dark field was used in Paper II to show the occurrence of h-AlN domains in the grain boundaries. 


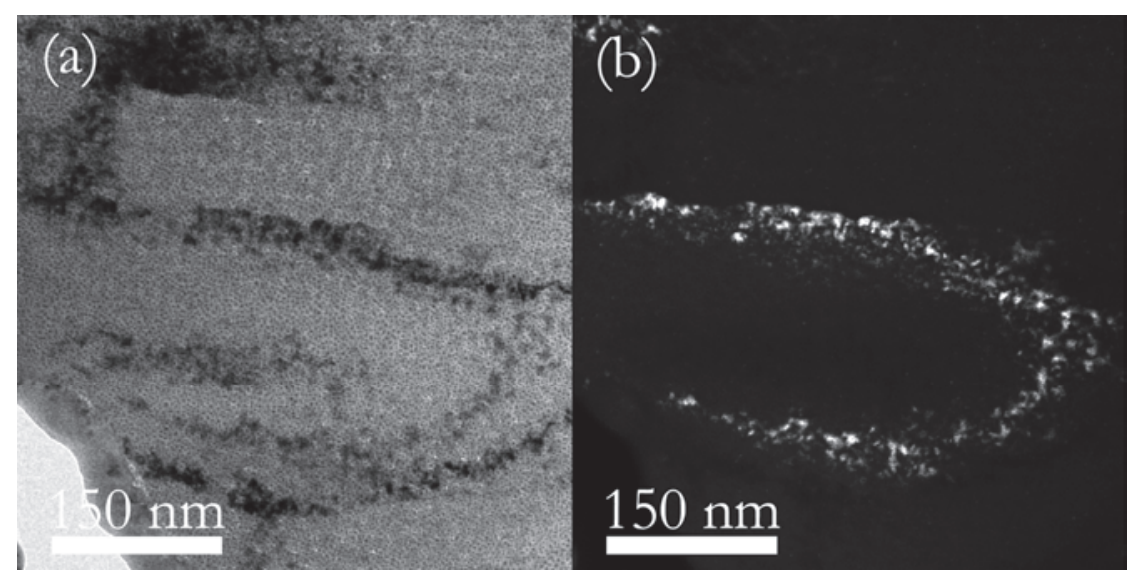

Figure 18. The difference between (a) bright field and (b) dark field TEM. The objective aperture was used to select only reflections from h-AlN in the dark field TEM. From Paper II.

At high magnifications, the main contrast is phase contrast which produces high resolution TEM (HRTEM) micrographs. With HRTEM, information about lattice spacing and orientation is obtained and it can thus be used to image, e.g., grain boundaries, interfaces between domains or dislocations. As was discussed above, bright and dark field imaging requires a single electron wave selected by the objective aperture whereas more than one wave is used to create the phase contrast in HRTEM imaging. When the electrons interact with the atomic potential, there is a phase shift in the wave function. Upon interaction with the transmitted, un-scattered wave, there is an interference variation in the image plane which produces lattice fringes. An example of an HRTEM image is seen in Figure 19, where a large h-AlN domain is incoherently surrounded by a c-TiN matrix. By a fast Fourier transform (FFT), seen in the inset, the crystallographic orientation of the matrix is revealed. Here, the c-TiN is oriented with the [002] zone axis (B), i.e., the crystallographic orientation parallel with the electron beam. The bright spots in the HRTEM are easily interpreted as atomic columns, this is though not necessarily true and care must be taken when analyzing HRTEM micrographs. 


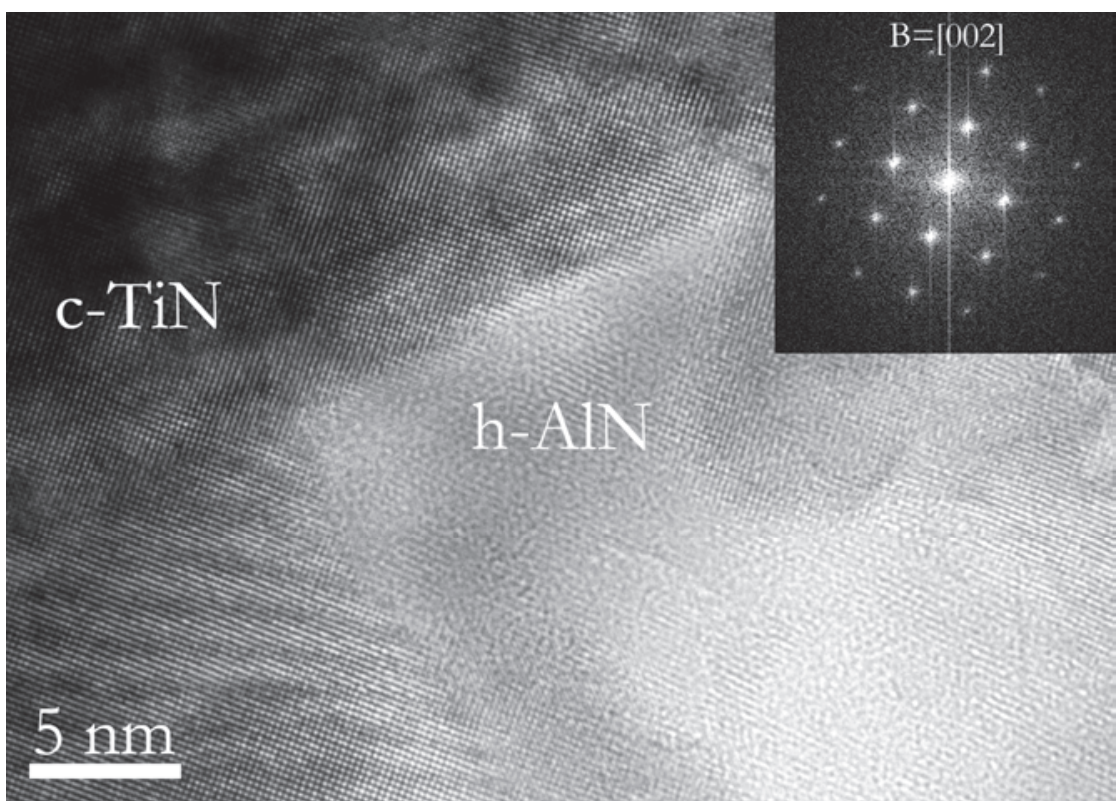

Figure 19. An example of a HRTEM micrograph from an annealed sample. The large domain of h-AlN is incoherently surrounded by c-TiN from where the FFT is performed. From Paper $V$.

\subsubsection{Electron diffraction}

A diffraction pattern is always formed when electrons interact with the sample and it can be imaged by viewing the diffraction plane on the fluorescent screen or CCD. Information about the crystal structure, lattice spacing and orientation is provided by the diffraction pattern. Electron diffraction is also used when orienting a sample to a low-index zone axis which is helpful prior to HRTEM imaging.

The principle behind electron diffraction is identical to XRD with the difference that the electrons are mainly scattered by the nuclei while the x-rays are scattered by core electrons. The main limitation in electron diffraction over XRD is the aberrations originating from the electromagnetic lenses resulting in less accuracy and resolution when determining lattice spacings. Compared to XRD, electron diffraction though occurs in significantly smaller volumes. Hence, it is possible to obtain information from features in the nanometer region, such as single grains in a polycrystalline coating. This is often used in combination with a selected area aperture which is introduced in the image plane. 


\subsubsection{Scanning transmission electron mic rosc opy}

In the TEM imaging modes discussed above, a parallel and broad electron beam is used to illuminate the entire sample. In the scanning transmission electron microscope (STEM), the electron beam is instead defined into a nano probe which is scanned across the specimen, similar to an SEM. In most STEM modes, the electrons are detected by a high angle annular dark field (HAADF) detector, although both bright and dark field detectors can be used in a STEM as well. The HAADF detector is positioned in the diffraction plane around the transmitted beam and detects the scattered electrons. Thus, the intensity in a STEM micrograph is mainly diffraction and Z-contrast. Consequently, bright contrast is seen from grains fulfilling the Bragg condition or from heavier elements in the sample, often with Z-contrast as the dominating mechanism. When combined with an energy dispersive $\mathrm{x}$-ray spectroscopy (EDS) detector, STEM mode enables the acquisition of elemental information in the studied sample. This is valuable as it enables the possibility to map elemental distributions in, e.g., decomposed regions, grain boundaries or the tool-chip interface (see Figure 32 in Chapter 7).

\subsubsection{Energy dispersive $x$-ray spectrosc opy}

During the interaction with the sample, core electrons in the atoms are knocked out by the transmitting electrons. This creates an electron hole in the atom which increases its energy. To minimize the energy, the hole is filled by an electron in a higher energy level to bring the atom to its ground state, and the energy gain is released as an x-ray photon. As the transitions between different electron energy levels are characteristic for all atoms, the detection of the x-ray spectrum provides elemental information of the sample.

This is however not possible for lighter elements, as the emitted x-rays are absorbed by the detector window and the detection of nitrogen in TiAlN is for instance limited. EDS detectors are often equipped in both SEM and STEM. In this work, EDS/SEM was mainly used to obtain average Ti/Al compositions in the coatings whereas EDS/STEM was used to study the spinodal decomposition of TiAlN.

\subsubsection{TEM sample preparation}

The TEM samples investigated in this thesis were prepared with either conventional preparation, focused ion beam (FIB) or powder particles prepared by grinding. In conventional TEM sample preparation, a diamond saw is used to cut the samples in pieces with dimensions similar to the desired TEM grid (normally $1.8 \times 1.0 \times 0.5 \mathrm{~mm}^{3}$ ) after which two pieces are mounted in the grid with the coating sides facing each other. The grid with pieces is then baked in a powder mixture of graphite and araldite, which attaches the 
pieces to the grid. The baked sample is then polished with diamond polishing papers to a thickness of around $50 \mu \mathrm{m}$. Several diamond polishing papers are used with a decreasing size of diamond grains until a mirror like surface is achieved. The mechanical polishing is followed by final thinning in an argon ion miller using an ion energy of $5 \mathrm{keV}$. Final milling is performed with a lower energy $(<1 \mathrm{keV})$ to reduce the ion damage. A completed prepared sample usually contains regions with a thickness less than $100 \mathrm{~nm}$ which is in general sufficient for electron transparency.

For samples too small for conventional sample preparation, as in Paper II, or for samples selected from specific region of interest, as in Paper I, the FIB is instead the preferred choice for TEM preparation. As is seen in Figure 20, a FIB is an SEM equipped with an additional ion column angled at $54^{\circ}$ with respect to the electron column. In the system used in this thesis, the ion and electron beam coincides at a working distance of $4.9 \mathrm{~mm}$.

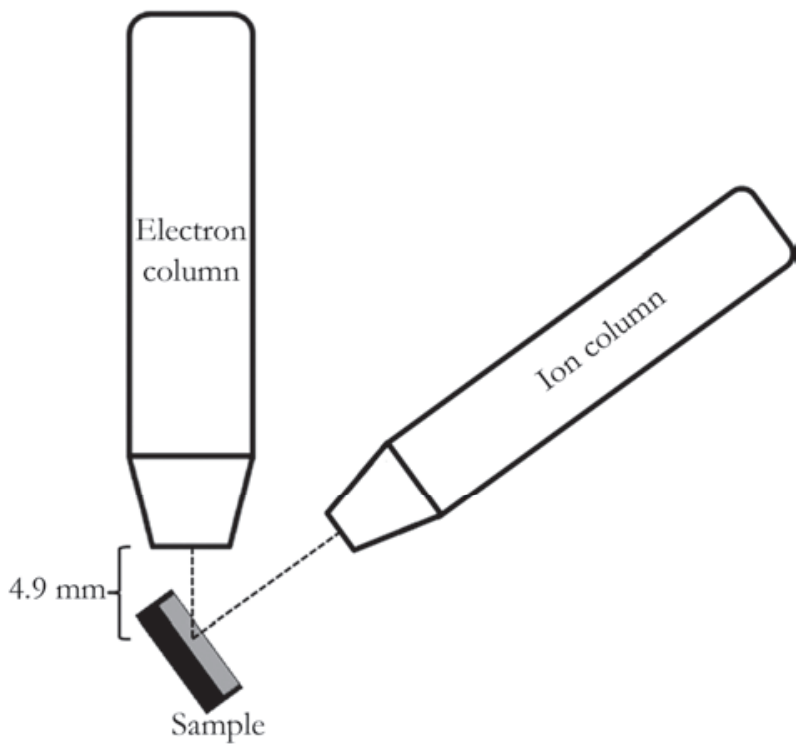

Figure 20. A schematic picture of the FIB setup used in this work. The electron an ion column coincides at a working distance of $4.9 \mathrm{~mm}$

In the ion column, gallium ions are accelerated from a liquid gallium source. The gallium ion beam is focused and scanned with electromagnetic lenses, similar to the electron beam. During ion bombardment of the sample surface, simultaneous emission of secondary electrons occurs. Thus, ion imaging is possible by a detection of the secondary electrons with the 
standard SEM detectors. As the stopping power is much larger for ions compared to electrons [111] the imaging is more surface sensitive, an advantage used in the helium ion microscope [112]. In a FIB however, the larger momentum of the $\mathrm{Ga}$ ions is used to sputter away sample atoms from the surface layer by layer.

A common technique to obtain a TEM sample is the lift-out technique, described by Langford et al. [113] and summarized in Figure 21. In the first step, shown in (a), a rectangular strip $\left(2 \times 2 \times 20 \mu \mathrm{m}^{3}\right)$ of platinum is deposited on the sample surface for protection. The platinum layer is deposited by letting platinum gas into the vacuum chamber via a gas injection system where after the gas is cracked on the surface by the ion beam. For surface sensitive samples, a slower deposition can also be performed with the electron beam. This is followed by ion milling of two trapezoids on each side of the platinum strip with a depth of $\sim 10 \mu \mathrm{m}$ until a freestanding sample with an approximate thickness of $800 \mathrm{~nm}$ is left (b). A micromanipulator is then introduced and attached on the sample with platinum. After attachment of the micromanipulator, the sample is cut and lifted out, shown in top view (c) and side view (d), after which the sample is welded on a TEM copper grid. The sample is further thinned and polished with decreasing ion currents until electron transparency is achieved, as shown in (e) and (f). The secondary electron detector is often used during final thinning as the sample appears brighter with the decreasing thickness, visualized in (f).
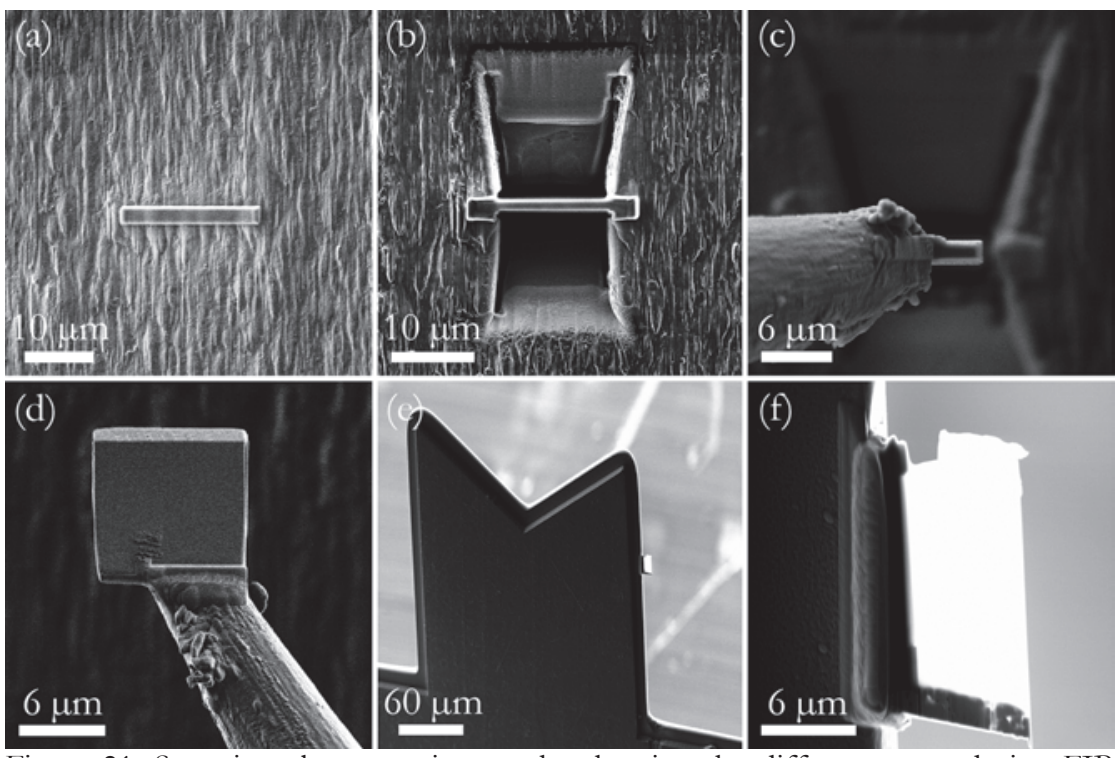

Figure 21. Scanning electron micrographs showing the different steps during FIB preparation of TEM samples. 


\subsection{Nanoindentation}

Measuring the hardness of hard coatings with indentation requires an instrument capable of only penetrating the coating without being influenced by the mechanical properties of the underlying substrate. This excludes traditional methods such as Vickers, Rockwell and Brinell testing due to their high loads during indentation. Instead, nanoindentation is commonly used with a load in the $\mathrm{mN}$ regime. During indentation, sensors detect the indenter displacement and force which results in a force-displacement plot, as is seen in Figure 22.

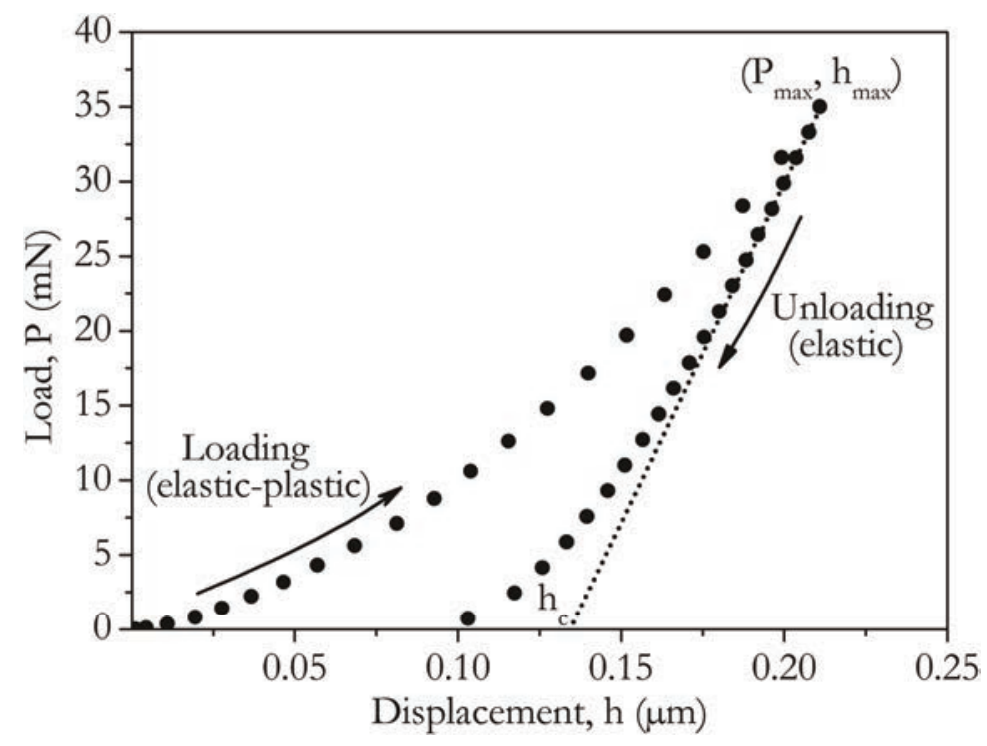

Figure 22. Example of a load-displacement curve during nanoindentation

From the load-displacement curve, the hardness is calculated with the Oliver and Pharr method [114] which is here summarized. During indentation, the surface around the indenter is displaced, $h_{s}$, which together with the contact depth, $h_{c}$, corresponds to the total displacement, $h_{\max }$. With $\mathrm{h}_{\mathrm{s}}$ dependent on the contact stiffness, $\mathrm{S}=\mathrm{dP} / \mathrm{dh}$, and maximum load, $\mathrm{P}_{\max }$, the contact depth is accordingly found from the load-displacement curve, see Eq. (16).

$h_{c}=h_{\max }-h_{s}=h-\epsilon \frac{P_{\max }}{d P / d h}$ 
where $\epsilon$ is dependent on indenter geometry, in this work 0.75 for the Berkovich geometry. As is seen in Figure 22, the contact stiffness is only measured in the beginning of the unloading where the contact area is constant. The indenter geometry also determines the relation between the contact depth and contact area (A), which for a Berkovich indenter is:

$A=24.5 h_{c}^{2}$

The hardness is then defined as the ratio between the maximum load and the contact area:

$H=\frac{P_{\max }}{A}$

Prior to the hardness measurements, the arc evaporated coatings are mechanically polished with diamond polishing papers. The reason is to exclude the impact of the intrinsic high surface roughness of the arc coatings, generated from the droplets. During nanoindentation, regions free of droplets are selected to measure the true hardness of the coating (c.f Figure 8). 


\section{High pressure techniques}

Two different high pressure techniques, the diamond anvil cell (DAC) and the multi anvil press (MA), have been used in this thesis. Both methods were invented in the 1950s [115-117] and are traditionally used in geo-sciences to simulate earth core conditions.

\subsection{Diamond anvil cell}

A DAC consists of two opposing diamonds with a metal gasket in between, schematically shown in Figure 23. In the gasket, a hole with a typical diameter of a few hundred $\mu \mathrm{m}$ is drilled after which the sample is inserted.

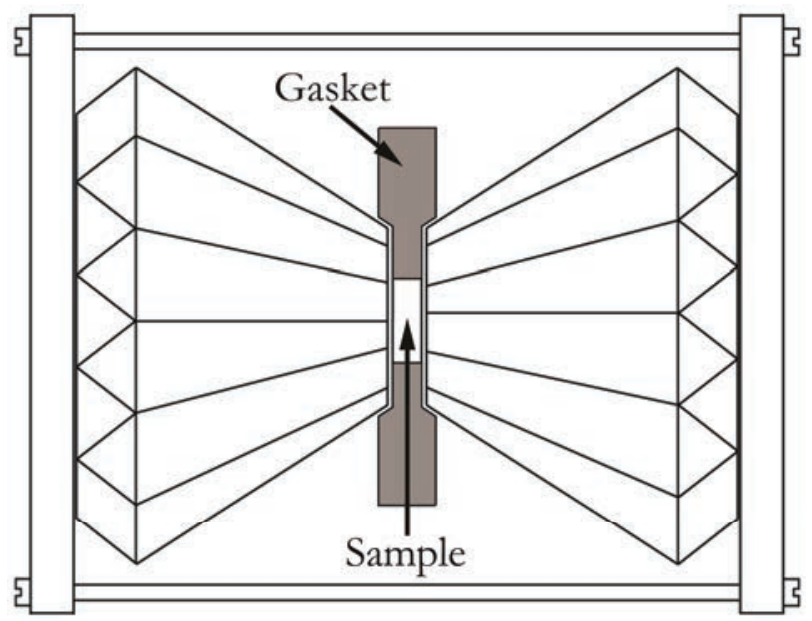

Figure 23. Schematic picture of a DAC, typical diameter of the hole containing the sample is a few hundred micrometers. 
Because of the small dimensions defined by the opposing diamonds, very large pressures $(>100 \mathrm{GPa})$ are obtained using very little force, for example by manually tightening the anvil screws. As diamonds are transparent to $\mathrm{x}$-ray radiation, crystallographic characterization can be performed in-situ. However, parts of the DAC do absorb the x-rays and a high brilliance x-ray source is generally needed where synchrotron facilities are the principal choice. In this thesis, the DAC experiments were characterized ex-situ with an in-house x-ray diffractometer.

Dependent on the application, there is a wide range of gasket materials from low- $Z$ materials such as boron [118] to high- $Z$ materials such as tungsten or rhenium [119]. In Paper II, rhenium was used due to its high melting temperature of $\sim 3200{ }^{\circ} \mathrm{C}$ [120] and inertness. To ensure a concentric hole, the gasket with an approximate thickness of $250 \mu \mathrm{m}$ was pre-indented, to a remaining thickness of tens of micrometers, with the diamond anvils by a closing and opening procedure. The final hole, with an approximate diameter of $125 \mu \mathrm{m}$, was then drilled with a spark erosion drill [121] which removes material through an electrical discharge. Upon completion of the hole, powder grains of the sample were loaded together with a pressurizing medium/thermal insulator and ruby particles where the latter was used to determine the pressure, see below.

\subsubsection{Heating of the DAC}

Heating of the sample is performed with either laser or electrical heating, dependent on the desired temperature ranges [122-125], both of them with advantages and disadvantages. During electrical heating, for temperatures from room temperature up to $1200{ }^{\circ} \mathrm{C}$, the entire pressure chamber or DAC is heated. This yields a heating with small temperature gradients $\left(<50{ }^{\circ} \mathrm{C}\right)$ where the temperature is stable for several hours and easily controlled and regulated with thermocouples. The whole chamber heating though puts a limitation to the upper temperature as the risk of graphitization of the diamond or welding of the gasket to the diamonds increases with increasing temperatures. A further disadvantage with the electrical heating is a pressure variation during heating which is induced by the different thermal coefficients of different parts of the DAC and the sample. Hence, the applied force to the diamonds needs to be adjusted during heating to maintain the pressure.

During laser heating, the risk of graphitization of the diamonds is greatly reduced as the heating is localized to a thermally insulated sample. This enables a temperature range from around $1000^{\circ} \mathrm{C}$ to above $5000{ }^{\circ} \mathrm{C}$, although with much larger gradients $\left(>100^{\circ} \mathrm{C}\right)$ and a fluctuating temperature. The large temperature gradients are a result of the localized heating in the laser spot and if in-situ experiments are conducted, the x-ray beam must be focused in the hot spot. During heating, the temperature is determined at the sample surface 
from the spectrum of the radiation. Together with the assumption of grey body radiation during the experiment where the high temperature and high pressure dependence of the emissivity is inexact, large uncertainties in the temperature measurement are induced.

Another issue with laser heating is the need of a thermal insulator and a pressurizing medium to protect the diamonds and enable a nearly hydrostatic pressure. Preferably, inert gases such as argon or neon are used but at high temperatures and high pressures they easily leak from the pressure chamber [126]. Common materials of thermal insulators at higher temperatures and pressures include $\mathrm{Al}_{2} \mathrm{O}_{3}, \mathrm{MgO}, \mathrm{BN}, \mathrm{CsCl}$ and $\mathrm{NaCl}$ [127]. For in-situ experiments involving diffraction, the choice of thermal insulator is crucial due to possible overlap of the diffraction peaks with the sample peaks, particularly as the sample volume in general is considerable smaller. In this thesis, laser heating with a double-side laser system [125,128] was used to reach higher temperatures compared to the $\mathrm{MA}$ experiments. $\mathrm{NaCl}$ was used as a thermal insulator due to little overlap with the diffraction peaks of TiAlN.

\subsubsection{Determination of pressure}

An accurate determination of the pressure inside a DAC is critical and cannot be directly calculated from the applied load. Instead, a standard material, e.g., ruby, quartz or Sm-doped $\mathrm{Y}_{3} \mathrm{Al}_{5} \mathrm{O}_{12}$ [129-131], is loaded in the pressure cell. The chosen standard material must have a known change in a measurable physical property with pressure. For instance, one of the most common is the fluorescence shift of ruby, which was also used in this thesis. By illumination of ruby with laser, a light spectrum is emitted by fluorescence due to excitations and relaxations of the atoms. As the peaks associated to ruby in the fluorescence spectrum are linearly shifted with pressure [132] the corresponding pressure can be calculated. This method is often used both before and after heating to ensure that no decompression has occurred during the heating stage. There is though a temperature dependence of the ruby fluorescence, so measuring the pressure during annealing requires other materials with a known equation of state at both elevated pressures and temperatures.

\subsection{Multi a nvil press}

The advantage with MA over DAC is the use of larger samples (volumes of $\mathrm{mm}^{3}$ instead of $\mu \mathrm{m}^{3}$ ) which provides better statistics. However, large forces are required to obtain the elevated pressure with greater dimensions of the press as a consequence. This complicates in-situ measurements and the general handling of the instrument as compared with the DAC. However, at some synchrotron beam lines, e.g., APS in Chicago, Spring- 8 in Japan and ESRF in 
France [133], stationary MAs exist with dedicated pathways for the x-ray beam.

To conduct a MA experiment, the sample is loaded in a cylindrical capsule manufactured of an inert material, for example platinum. The size of the capsule, in combination with the anvil force, determines the maximum obtained pressure. For better statistics, an increased sample volume is desired and there is hence a tradeoff between pressure and sample volume. The filled platinum cylinder is further enclosed by a cylindrical graphite heater and a thermo insulating tube made of $\mathrm{MgO}$ or $\mathrm{ZrO}_{2}$. The cylinder is then loaded into a pressure transmitting octahedron made of $\mathrm{MgO}$ which is further surrounded symmetrically by eight tungsten anvils. The setup with four of the tungsten anvils is seen in Figure 24.

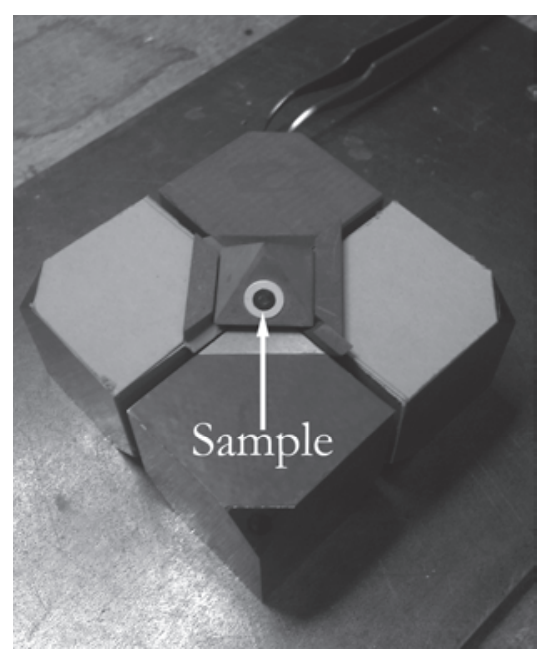

Figure 24. Multi anvil sample inside an octahedron, surrounded by four out of eight tungsten anvils (the length of one side is approximately $100 \mathrm{~mm}$ ).

The anvil package is placed in the press which is followed by a hydraulic compression to a desired pressure. A direct measurement and control of the pressure as in the DAC is though not possible, instead the pressure is calibrated with the hydraulic pressure from precedent calibrated measurements using a standard material. The heating of the sample is performed with electrical heating where the current flows between two of the corner anvils through the graphite cylinder. The temperature can be controlled either with a thermocouple or by a previous calibration between the temperature and current. 
The MA experiments (1000-ton or 1200-ton) used in this thesis were performed with platinum cylinders of either $1 \mathrm{~mm}$ in radius and $3.5 \mathrm{~mm}$ in height or $0.8 \mathrm{~mm}$ in radius and $2.8 \mathrm{~mm}$ in height, depending on pressure ranges. During the compression, a sintering of the powder sample occurred due to the high pressures and temperatures which simplified TEM sample preparation with FIB.

\subsection{Sample preparation}

As the experiments in the DAC and MA require powder samples, a removal of the coating from its substrate is necessary. This is done chemically and thin iron sheets are thus used as substrates during deposition instead of tungsten carbide inserts. After deposition, the backsides of the sheets are mechanically grinded. The grinding has two purposes, removal of the small amounts of coating grown on the backside and providing a rough surface for the hydrochloric etching. The sheets are then immersed in hydrochloric acid whereupon the iron is dissolved, leaving the coating as flakes. The flakes are cleaned in acetone and distilled water to remove all acid residues. Afterwards, the flakes are ground into a fine powder with a mortar and pestle. The same procedure was also used in Paper $V$ for the powder used during synchrotron measurements. 



\section{CHAPTER 7}

\section{Metal machining}

Metal machining includes a variety of operations, such as turning, milling or drilling where the former application has been used in this thesis. Despite extensive research, a complete understanding of the metal cutting process is still lacking. The reason is the complexity and diversity of the processes leading to metal cutting performance dependent on, e.g., the work material, the substrate material and shape, the coating material, the deposition method and external cutting parameters. This chapter introduces a few basic concepts for metal cutting with both published and unpublished examples.

\subsection{Temperature distribution}

During a turning operation, the measurement of temperature is far from straightforward. Some of the methods include the use of thermocouples [134], sensors deposited on the tools [135,136], pyrometers [137] and modeling [138]. In this work, a near infrared CCD detector [139-141] was used due to its high resolution $(\mu \mathrm{m})$ and ability to extract a temperature profile along the rake face. Measureable temperatures are in the range of $500-1000{ }^{\circ} \mathrm{C}$ with uncertainties of $10-30{ }^{\circ} \mathrm{C}$. The largest uncertainties arise from the emissivity values of the tool and the calibration of the CCD detector. The calibration is described in detail elsewhere [139-141] but involves using a black body cavity and a heated tool as references before measurements. The measurement setup is shown schematically in Figure 25 where a turning operation of a tube is performed. Due to the requirement of a clear line of sight between the detector and the tool, the turning operations are limited to dry conditions. To ensure observation of the cutting zone, the side of the tool is ground in advance, as is also seen in Figure 25. 


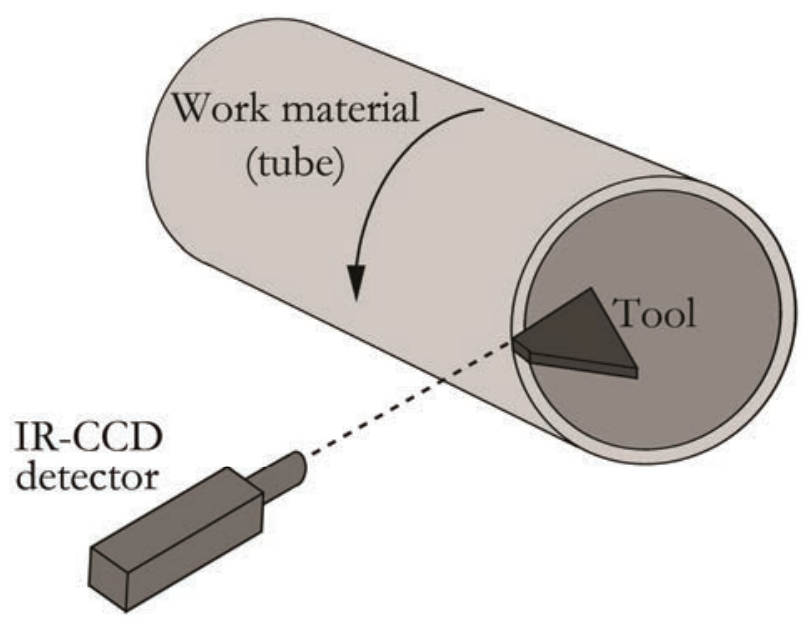

Figure 25. Schematic picture of the setup during temperature measurement. After [139].

In Paper I, temperature measurements were performed on $\mathrm{Ti}_{0.63} \mathrm{Al}_{0.37} \mathrm{~N}$ coated tools during turning in a hardened and tempered steel. The temperature distribution during turning with cutting speeds $\left(\mathrm{v}_{\mathrm{c}}\right)$ of 100,200 and $400 \mathrm{~m} / \mathrm{min}$ are seen in Figure 26 using a feed (f) of $0.3 \mathrm{~mm} / \mathrm{rev}$ and a depth-of-cut $\left(a_{\mathrm{p}}\right)$ of $3 \mathrm{~mm}$. Temperature measurements were also performed on $\operatorname{Ti}_{0.33} \mathrm{Al}_{0.67} \mathrm{~N}$ but no significant changes outside the uncertainties were noticed. The measurement time was 20-30 seconds whereupon thermal equilibrium was achieved. Hence, heating rates in the order of several thousand degrees per minute is normally achieved during metal cutting.
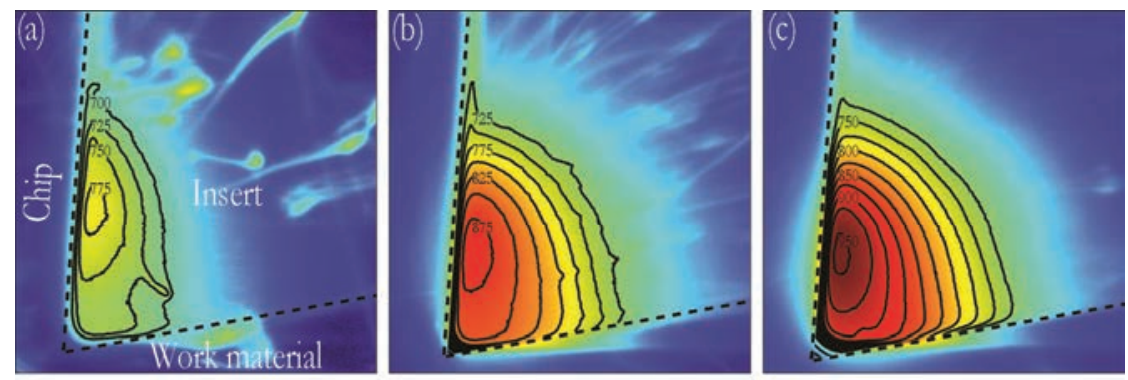

$550600650701, \quad 510850900$

Figure 26. Thermal maps showing the temperature $\left({ }^{\circ} \mathrm{C}\right)$ during cutting as measured with an IR-CCD detector at cutting speeds of (a) 100, (b) 200 and (c) $400 \mathrm{~m} / \mathrm{min}$. 
A position, a so called hot spot, on the rake face can be seen for all cutting speeds. With increasing cutting speed, the hot spot moves closer to the insert tip. However, as the contact length between the insert and the chip also decreases with cutting speed, the hot spot is approximately located at half the contact length. During the turning operation, the work material is plastically deformed in the shear zone whereupon a chip is formed. The plastic deformation, in combination with the friction between the work material and the tool, generate the heat $[142,143]$. Thus, with increasing cutting speed, the average and maximum temperature is strongly dependent on cutting speed as the amount of sheared and sliding work material per time increases. Similar effects can be seen by increasing the feed. Extraction of the maximum temperatures gives temperatures around $780{ }^{\circ} \mathrm{C}$ at $100 \mathrm{~m} / \mathrm{min}, 890{ }^{\circ} \mathrm{C}$ at $200 \mathrm{~m} / \mathrm{min}$ and $960^{\circ} \mathrm{C}$ at $400 \mathrm{~m} / \mathrm{min}$ for this configuration.

\subsection{Stress distribution}

During cutting operations, the measurement of cutting forces is straight forward with the use of a dynamometer. The determination of a correct stress distribution along the cutting edge is however more challenging and often FEM modeling [144-146] is used in combination with experimental parameters. In this work, an analytical model described in detail by Chandrasekaran et al. $[138,139]$ was used to model the stress distribution during orthogonal turning. Parameters used in the model are the chip thickness, contact length, work material shear strength and the measured cutting forces. Assumptions in the model include 2D loading, a sharp tool and no curling of the chip. This is likely to cause deviations from the real stress distribution but the results were mainly used to show the occurrence of stresses in the GPa region during turning. The modelled normal and tangential stress distributions are seen in Figure 27 as a function of the contact length for cutting speeds of 100,200 and $400 \mathrm{~m} / \mathrm{min}$.

The position of the peak normal stress occurs at the tool tip and decreases almost linearly as the distance from the tip along the contact length increases. The peak values are around $2 \mathrm{GPa}$ and essentially not dependent on the cutting speeds although the contact lengths varies. The values of the tangential stress are lower with peak stresses around $0.8 \mathrm{GPa}$ with a slight decrease as the cutting speed increases. This could partly be explained by the thermal softening of the work material as the average temperature increases with cutting speed. 


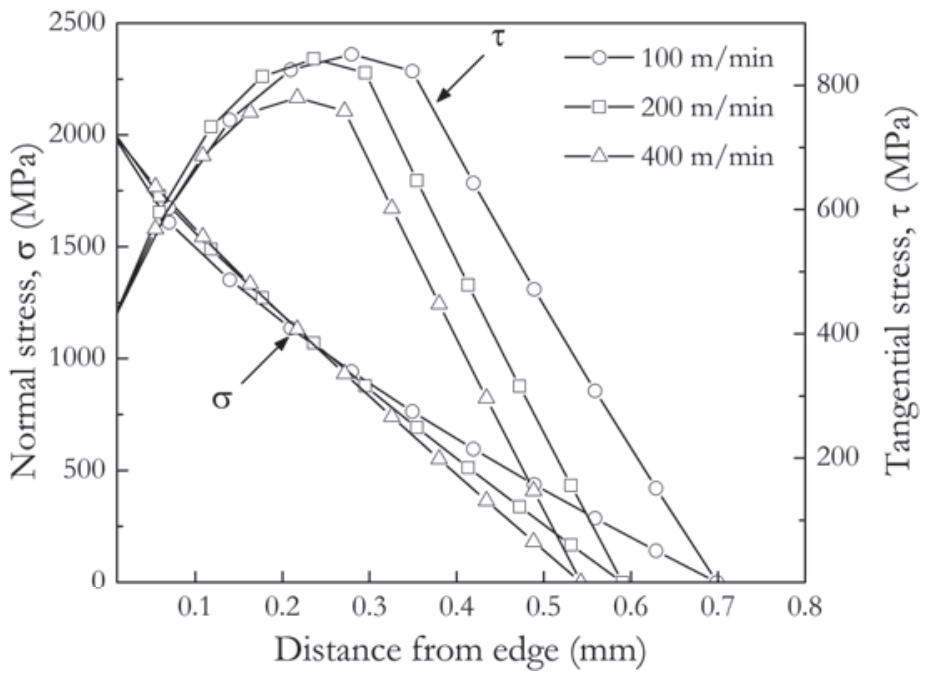

Figure 27. Stress distribution along the rake face at (a) 100, (b) 200 and (c) $400 \mathrm{~m} / \mathrm{min}$. From Paper I.

\subsection{Wear}

The high thermal and mechanical loads on the cutting tool eventually lead to wear of the coating. During a turning operation, control and prediction of the wear is critical as it may lead to cutting force fluctuations and an impaired surface finish of the work material. The most common wear mechanisms are shown in Figure 28 and are flank (I), crater (II) and notch wear (III).

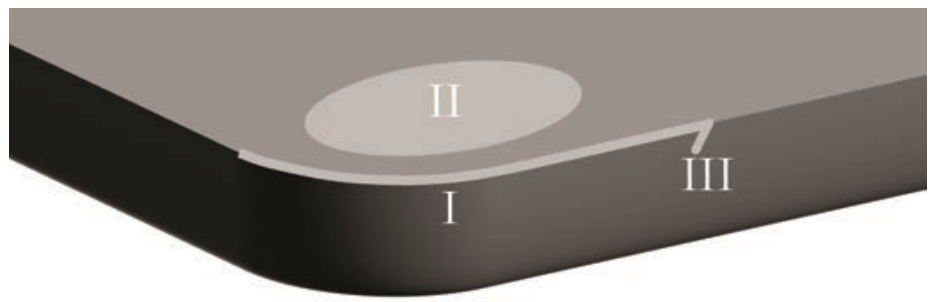

Figure 28. Schematic picture showing three of the major wear types: (I) flank wear, (II) crater wear and (III) notch wear.

The notch wear appears in the border zone between the atmosphere and the work material, i.e., at the depth of cut. This wear is most pronounced when cutting in deformation hardening work materials such as stainless steels [147]. As it occurs in presence of oxygen, the notch wear is typically reduced with oxidation resistant coatings [148]. 
The crater wear begins on the rake face at around half of the contact length where the highest temperature and frictional stress are present. During cutting, the crater wear gradually evolves with time towards the cutting edge, where the rake and flank face meet, as is illustrated in Figure 29. The origin of the crater wear is dependent on the work material and cutting parameters but is often referred to as a combination of chemical wear from diffusion [149], abrasive wear from the chip sliding [150] and plastic deformation of the coating $[151,152]$. A direct improvement of the crater wear resistance is also obtained by increasing the thickness of the coatings. As the crater reaches the edge, a complete breakdown of the cutting edge occurs and control of the crater wear is therefore important. However, monitoring and prediction of the crater wear is difficult compared to the flank wear (which can be monitored from the cutting forces).

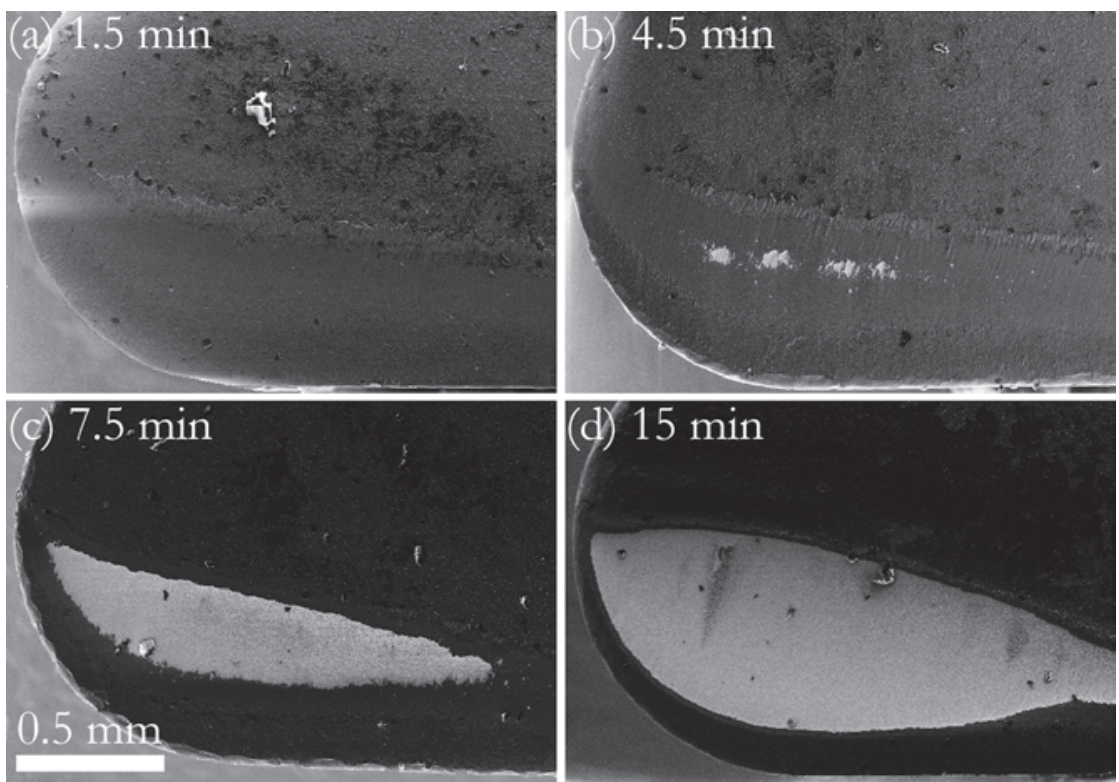

Figure 29. Evolution of crater wear with cutting time. The substrate (bright area) is firstly exposed after a cutting time of $4.5 \mathrm{~min}$.

The progression of the flank wear is attributed to abrasive wear from hard inclusions, e.g., oxides or carbides, in the work material [153] and increasing flank wear reduces the surface finish of the final work piece material. As the resistance against abrasives increases with hardness, the hot hardness is one of the key parameters determining the flank wear. In Figure 30, the hot hardness up to $600{ }^{\circ} \mathrm{C}$ is shown for TiN, Ti0.75 $\mathrm{Al}_{0.25} \mathrm{~N}$ and $\mathrm{Ti}_{0.45} \mathrm{Al}_{0.55} \mathrm{~N}$. Both TiAlN coatings are slightly harder compared to TiN at room temperature. The thermal softening is close to linear for all coatings up to $400{ }^{\circ} \mathrm{C}$ but the 
hardness values at $600{ }^{\circ} \mathrm{C}$ show significant differences between the coatings. The hardness value of $\mathrm{Ti}_{0.45} \mathrm{Al}_{0.55} \mathrm{~N}$ is here twice as large compared to TiN with $\mathrm{Ti}_{0.75} \mathrm{Al}_{0.25} \mathrm{~N}$ in between. The results further confirm previous hardness values measured in room temperature after annealing. Although results for $\mathrm{Ti}_{0.33} \mathrm{Al}_{0.67} \mathrm{~N}$ are lacking in Figure 30, it would likely reveal a similar or higher hardness than $\mathrm{Ti}_{0.45} \mathrm{Al}_{0.55} \mathrm{~N}$.

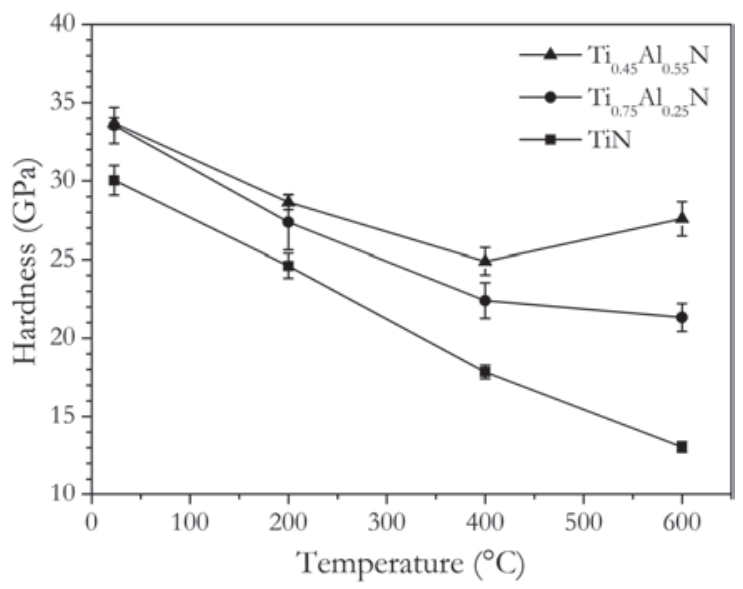

Figure 30. In-situ hot hardness of TiN, $\mathrm{Ti}_{0.75} \mathrm{Al}_{0.25} \mathrm{~N}$ and $\mathrm{Ti}_{0.45} \mathrm{Al}_{0.55} \mathrm{~N}$.

As is shown in Figure 31, there is also a major difference in flank wear resistance for (a) TiN and (b) $\mathrm{Ti}_{0.50} \mathrm{Al}_{0.50} \mathrm{~N}$ after two identical cutting operations $\left(v_{c}=200 \mathrm{~m} / \mathrm{min}, \mathrm{f}=0.2 \mathrm{~mm} / \mathrm{rev}, \mathrm{a}_{\mathrm{p}}=2 \mathrm{~mm}, \mathrm{t}=15 \mathrm{~min}\right)$. Here, the flank wear in TiN is irregular with a maximum of $0.68 \mathrm{~mm}$ which far exceeds the stopping criterion of $0.30 \mathrm{~mm}$ generally used in cutting tests [154]. On the contrary, $\operatorname{Ti}_{0.50} \mathrm{Al}_{0.50} \mathrm{~N}$ shows a regular flank wear averaged around $0.12 \mathrm{~mm}$.
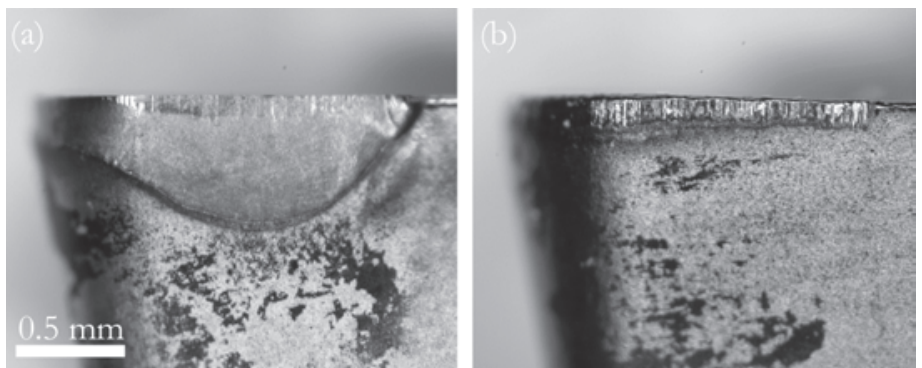

Figure 31. Flank wear for a a tool coated with (a) TiN and (b) $\mathrm{Ti}_{0.50} \mathrm{Al}_{0.50} \mathrm{~N}$ 


\subsection{Chemical interactions}

The high temperature during metal cutting increases the diffusion rate and hence the chemical interactions between the coating and its surroundings. At the tool-chip-interface, an adhered layer containing species from the work material, the coating and the atmosphere is apparent during cutting [155]. An example of the adhered layer is shown in Figure 32 with corresponding elemental EDS maps for Al, Ti, Si, S, Mn, Fe and O.

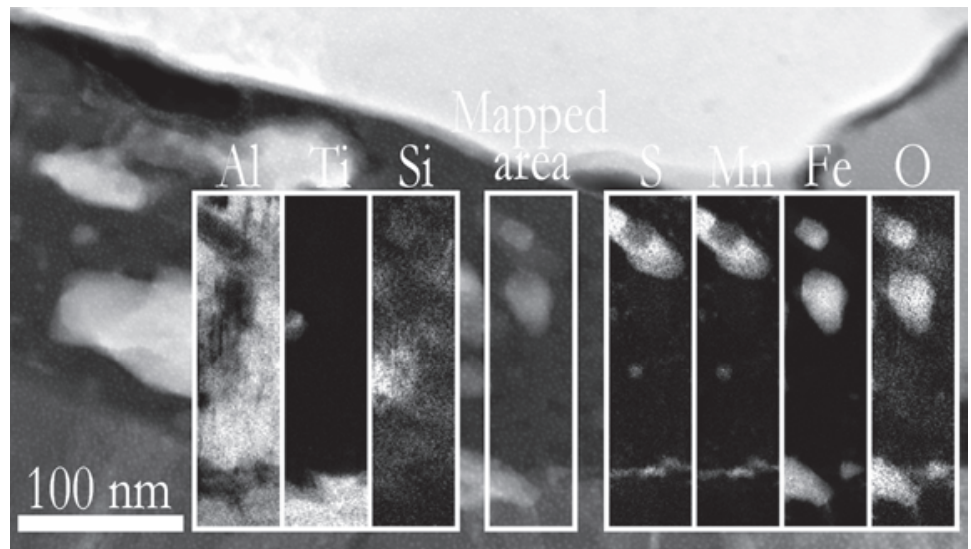

Figure 32. STEM micrograph of the adherent layer with additional elemental EDS maps for Al, Ti, Si, S, Mn, Fe and O.

The STEM sample, $\mathrm{Ti}_{0.33} \mathrm{Al}_{0.67} \mathrm{~N}$, was extracted from a coating used in metal cutting of a tempered steel $(\mathrm{C} 45 \mathrm{E})$ and prepared with FIB at a position close to the crater. The uppermost bright layer was analyzed with an EDS line scan (not shown) and consists mainly of Fe from the work material. Between the Fe rich layer and the coating is an $\mathrm{Al}$ rich layer with constituent elements from the work material ( $\mathrm{FeO}, \mathrm{MnS}$ and $\mathrm{Si}$ ) with no traces of $\mathrm{Ti}$, apart from the particle seen in the middle, in the adherent layer. The abundance of $\mathrm{Al}$ in the work material limits the origin of the Al-rich layer to out-diffusion from the coating, possibly followed after loss of nitrogen in the coating. The outdiffusion of $\mathrm{Al}$ could also be a contributor to the above mentioned crater wear $[156,157]$.

Chemical interactions also occur in the interface between the substrate and the coating, due to the elevated temperature during metal cutting. Cobalt, used as a binding agent in the tungsten carbide, is commonly diffusing from the substrate into the coating, typically in the grain boundaries due to the higher diffusivity [158]. The poisoning of cobalt in the coating is detrimental for its mechanical properties and a common prevention method is to deposit an interlayer, such as TiN, between the substrate and the coating. 



\section{CHAPTER 8}

\section{Summary of included papers}

\subsection{Paperl}

The background behind this paper was the theoretical prediction by Alling et al. [92] of a promoted spinodal decomposition by an external pressure. Due to a shoulder in the isostructural phase diagram, the effect was expected to be most prominent for an $\mathrm{Al}$ content around 40 at- $\%$. To investigate the pressure effect during metal machining, Ti0.6 $\mathrm{Al}_{0.4} \mathrm{~N}$ coatings were deposited on tungsten carbide inserts which were used in a longitudinal turning operation. The time in cut was $10 \mathrm{~min}$ with a cutting speed of $200 \mathrm{~m} / \mathrm{min}$, feed of $0.3 \mathrm{~mm} / \mathrm{rev}$ and a $3 \mathrm{~mm}$ depth of cut. Using identical cutting parameters, orthogonal metal cutting was also executed while measuring the cutting forces and temperature distribution.

Additionally, heat treatments with a 10 min isothermal step of $900{ }^{\circ} \mathrm{C}$ and $1000{ }^{\circ} \mathrm{C}$ respectively were performed for comparison with the inserts used in metal cutting. The $e x$-situ characterization was mainly performed with STEM. The results showed a peak temperature slightly below $900{ }^{\circ} \mathrm{C}$ and a normal stress of $2 \mathrm{GPa}$, both of them decreasing along the rake face. Connected with the inhomogeneous temperature distribution, the spinodal wavelength was shown to vary along the rake face, from around 5 to $11 \mathrm{~nm}$. By comparing the wavelength after metal cutting with the heat treated samples, the effect of the applied external pressure levels was shown to promote the spinodal decomposition, in line with the theoretical prediction.

\subsection{Paperll}

The aim of Paper II was to show the suppression of the c-AlN to h-AlN transformation in $\mathrm{Ti}_{0.6} \mathrm{Al}_{0.4} \mathrm{~N}$ at high pressures and high temperatures (HPHT). This was utilized with the multi anvil press and diamond anvil cell techniques with temperatures and pressures up to $2200{ }^{\circ} \mathrm{C}$ and $23 \mathrm{GPa}$. Prior to the HPHT experiments, the coating was removed from an iron substrate 
leaving $\mathrm{Ti}_{0.6} \mathrm{Al}_{0.4} \mathrm{~N}$ as powder. All samples were exposed to $\mathrm{T}_{\max }$ for $10 \mathrm{~min}$ before quenching, after which they were characterized ex-situ using XRD. Microstructural information was also obtained from selected samples using TEM. Additionally, a pressure/temperature phase diagram of pure AlN showing the equilibrium line between c-AIN and h-AIN were calculated using first principles calculations.

Results of the first principle calculations showed a stabilization of c-AlN over h-AlN with an increased pressure at all temperatures. In addition, the negative curvature of the equilibrium line also suggested an increased stability of c-AlN with an increased temperature at elevated pressures. The experimental XRD results showed an excellent agreement with the theoretical findings as an increased temperature at isotherms as well as an increased pressure at isobars stabilized c-AlN. It was also concluded, by comparing the experimental values of $\mathrm{Ti}_{0.6} \mathrm{Al}_{0.4} \mathrm{~N}$ with the theoretical phase diagram of $\mathrm{AlN}$, that the addition of Ti into AlN further stabilized c-AlN.

\subsection{Paper III}

In Paper III, the consequences of the elastic anisotropy in $\mathrm{Ti}_{1_{-}} \mathrm{Al}_{\mathrm{x}} \mathrm{N}$ [78] on the microstructure during spinodal decomposition was studied. Firstly, $\mathrm{Ti}_{1-\mathrm{x}} \mathrm{Al}_{\mathrm{x}} \mathrm{N}$ with various $\mathrm{Al}$ content $(\mathrm{x}=0.31,0.37,0.47,0.66)$ was deposited on tungsten carbide substrates and exposed to metal cutting tests and heat treatments (up to 800,900 and $1000{ }^{\circ} \mathrm{C}$ ). After heat treatments, the hardness values of selected compositions were measured with nanoindentation whereas STEM at high symmetry zone axes was used to obtain microstructural information.

The hardness values showed a strong correlation between $\mathrm{Al}$ content and age hardening, similar to what had been published before, where the age hardening was most pronounced for $\mathrm{Ti}_{0.34} \mathrm{Al}_{0.66} \mathrm{~N}$. The STEM results for $\mathrm{Ti}_{0.34} \mathrm{Al}_{0.66} \mathrm{~N}$ showed a highly anisotropic microstructure where the c-TiN and c-AlN domains were aligned along the elastic compliant $<100>$ directions. This result was in excellent agreement with the spinodal decomposition theory in anisotropic systems. $\mathrm{Ti}_{0.63} \mathrm{Al}_{0.37} \mathrm{~N}$, i.e., close to the isotropic limit, instead showed a microstructure with randomly ordered domains. As discussed, the anisotropic microstructure demonstrates a shorter distance between the domains compared to the isotropic case, leading to an increased hardening [81].

\subsection{Paper $\mathbf{N}$}

The aim of this study was to investigate the microstructure and metal cutting behavior of bias-modulated $\mathrm{Ti}_{0.50} \mathrm{Al}_{0.50} \mathrm{~N}$. During deposition, the bias was instantly changed between $-35 \mathrm{~V}$ and $-70 \mathrm{~V}$ with different time periods, 
yielding bias-layer periods from 200 to $1200 \mathrm{~nm}$. As references, $\mathrm{Ti}_{0.50} \mathrm{Al}_{0.50} \mathrm{~N}$ and $\mathrm{Ti}_{0.33} \mathrm{Al}_{0.67} \mathrm{~N}$ were grown with fixed biases. All coatings were used in metal cutting tests with a cutting speed of $200 \mathrm{~m} / \mathrm{min}$, a feed of $0.2 \mathrm{~mm} / \mathrm{rev}$ and a $2 \mathrm{~mm}$ depth of cut. The time in cut was 1.5, 4, 7.5 and $15 \mathrm{~min}$ in order to quantify the progression of the flank and crater wear. The flank wear was measured with light optical microscopy and the crater wear with scanning electron microscopy. The preferred orientations of the coatings were analyzed with XRD while microstructural information was realized with TEM.

For the fixed bias coatings, the results showed an increased residual stress and a transition from a (100) to a (111) preferred orientation with the bias change from $-35 \mathrm{~V}$ to $-70 \mathrm{~V}$. All the bias-layered coatings showed a (111) preferred orientation slightly dependent on bias-layer period. The microstructure in the fixed bias coatings changed from a columnar structure to a feather like structure with refined grains. The bias-layered coatings revealed a periodic change in TEM contrast correlating with the bias period which was connected to differences in residual stress between the individual layers. The overall microstructure was found to be columnar with smaller grain sizes compared to the $-35 \mathrm{~V}$ fixed bias coatings. The combination of the layered microstructure, with small grains in a (111) preferred orientation and a small residual stress resulted in an improvement of both crater and flank wear resistance for all bias-layered coatings compared with the fixed-bias coatings.

\subsection{PaperV}

The cubic to hexagonal transformation of AlN in TiAlN has received little attention in the literature, despite its deteriorating effect on the mechanical properties of TiAlN. Thus, the aim of Paper $V$ was to gain a further knowledge on the detailed kinetics of the transformation. Here, the evolution of h-AlN in $\mathrm{Ti}_{0.55} \mathrm{Al}_{0.45} \mathrm{~N}$ and $\mathrm{Ti}_{0.36} \mathrm{Al}_{0.64} \mathrm{~N}$ at elevated isothermal temperatures was studied in-situ with synchrotron radiation. To enable quantitative information, the measurements were conducted on powder materials originating from coatings deposited on iron substrates. The main study was performed with WAXS, although SAXS was used to extract the critical wavelength of c-AlN at the onset of h-AlN. STEM was further used to acquire microstructural information.

The results showed a significantly higher transformation rate for $\mathrm{Ti}_{0.36} \mathrm{Al}_{0.64} \mathrm{~N}$ compared to $\mathrm{Ti}_{0.55} \mathrm{Al}_{0.45} \mathrm{~N}$ with an onset of the transformation around $50^{\circ} \mathrm{C}$ earlier. Despite the large deviation in transformation rate, both compositions showed similar activation energies as determined with a modified KJMA equation with $320 \pm 10 \mathrm{~kJ} / \mathrm{mol}$ for $\mathrm{Ti}_{0.36} \mathrm{Al}_{0.64} \mathrm{~N}$ and $350 \pm 40 \mathrm{~kJ} / \mathrm{mol}$ for $\mathrm{Ti}_{0.55} \mathrm{Al}_{0.45} \mathrm{~N}$. The critical wavelength of $\mathrm{c}-\mathrm{AlN}$ at the onset was determined to around $13 \mathrm{~nm}$ for both compositions. Because of the similar activation energies and critical wavelength, the difference in 
transformation rate was instead proposed to be correlated to the microstructural differences from the precedent spinodal decomposition. Due to the anisotropic microstructure and the higher $\mathrm{Al}$ content in ${ }^{1} i_{0.36} \mathrm{Al}_{0.64} \mathrm{~N}$ an interconnected microstructure is to a larger extent formed compared to $\mathrm{Ti}_{0.55} \mathrm{Al}_{0.45} \mathrm{~N}$ which enables a faster growth of the h-AlN nuclei. 


\section{Contributions to the field}

This is a summary of the author's opinion on how the work in this thesis has served to contribute to the field, based on the results in the papers:

- The promoted spinodal decomposition with an external pressure was shown experimentally. Additionally, the stabilization of c-AlN over h-AlN with an increased pressure as well as with an increased temperature at elevated pressures was shown experimentally.

- The effect of the inherent elastic anisotropy in TiAlN on the microstructure after spinodal decomposition was shown experimentally. The results contribute to a further understanding of the age hardening behavior during annealing of TiAlN.

- The growth of bias-modulated coatings $\mathrm{Ti}_{0.50} \mathrm{Al}_{0.50} \mathrm{~N}$ was investigated in terms of microstructural and metal cutting properties. The results showed an improvement in terms of both crater and flank wear resistance compared to reference coatings deposited with a fixed bias.

- Kinetics of the cubic to hexagonal AlN transformation in terms of transformation rates, activation energies and critical wavelengths was addressed in detail for two compositions commonly used on metal cutting inserts. The study can be used as a reference in future work concerning the growth of h-AlN in TiAlN based quaternaries. 



\section{CHAPTER 10}

\section{Future work}

This chapter provides the author's suggestions to future work based on the results presented in this thesis.

\subsection{In-situ pressure dependence of TIAIN}

The effect of pressure on the spinodal decomposition studied in Paper $I$ is based on ex-situ characterizations and an in-situ study would therefore provide important information. Such a study could be utilized with a diamond anvil cell or a multi anvil press in combination with synchrotron radiation. For statistics, i.e., a larger measured volume, the multi anvil press would be the preferred choice. With such an experimental setup, the evolution of the spinodal wavelength as a function of temperature and hydrostatic pressure could for example be studied with small angle x-ray scattering.

Similarly, an in-situ study of the pressure dependence on the stability of c-AlN over h-AlN is lacking. Such a study could be used to further investigate the pressure/temperature phase diagram shown in Paper II. Furthermore, the reversibility of the c-AlN to h-AlN transformation as a function of pressure could be studied.

\subsection{Pressure dependence of quatemary coatings}

The results of Paper II showed a shift of the equilibrium line between c-AlN and h-AlN towards lower pressures $(2-3 \mathrm{GPa}$ ) with the addition of Ti. This was, in the phase separated structure, attributed to a template effect where the surrounding c-TiN stabilized c-AlN with coherency strains. Also, single impurity calculations at $0 \mathrm{~K}$ indicated a similar shift in TiAlN compared to AIN. Despite this shift, the pressure to completely stabilize the cubic structure of AlN is higher than the actual pressure acting on the coating during metal cutting. However, previous publications have shown an improved thermal stability, at ambient pressures, upon further alloying TiAlN with a forth 
element [82-87]. It is likely that this trend at an ambient pressure is valid at elevated pressures as well and thus a further shift of the equilibrium line is realized for quaternary coatings, i.e., closer to pressure levels during metal cutting. Such a study should be conducted with the method described in Paper II for direct comparison with TiAlN.

\subsection{Kinetic description of quatemary coatings}

The study in Paper $V$ provides a detailed kinetic study of the c-AlN to h-AlN transformation in TiAlN. Due to the above mentioned improved thermal stability after alloying with additional elements, a similar study conducted on a TiAlN based quaternary would give valuable information about the activation energy, transformation rate and the critical wavelength. Due to the large dependence on $\mathrm{Al}$ content on the transformation rate, such a study should be conducted with similar Al contents as in Paper $V$. Although the main study in Paper $V$ is based on isothermal annealing, a different heating rate is likely to affect the spinodal decomposition and the nucleation of h-AlN. Hence, identical heating rates are required for a full comparison with the results of TiAlN in Paper $V$.

\subsection{In-situ a nnea ling in TEM}

Although Paper $V$ shows the in-situ transformation of h-AlN with XRD, an in-situ microstructural evolution is lacking. With the recent advantages of aberration corrected STEM and energy filtered TEM, such a study would be possible in combination with a high temperature sample holder. To complement the results in Paper $V$, the study should focus on the growth of the h-AlN but the study would also give valuable insight in the spinodal decomposition prior to the hexagonal transformation. For selection of suitable temperatures, both Paper $V$ and the study by Knutsson et al. [11] are valuable as references.

\subsection{Hot hardness of c oatings}

It is generally assumed that one of the factors determining the metal cutting performance, in terms of flank wear resistance, is the hot hardness of the coatings. Despite this, the majority of publications concerning the age hardening in TiAlN are performed at room temperature on annealed samples, i.e., the actual hot hardness of the coatings are lacking due to various of reasons. Firstly, nanoindentation is almost exclusively performed using a diamond indenter which is not stable at the temperatures relevant for metal cutting inserts due to for example graphitization or oxidation of the diamond. The small indentation depths up to a few hundred nanometers also increase 
the sensitivity of thermal drift during indentation. However, recent solutions to this include high temperature nanoindentation in vacuum [159], where the possibility to reach the relevant temperatures is higher. Measurements in a protective atmosphere are also possible, as was the case for Figure 30 but this also lowers the maximum temperatures obtained $[160,161]$. A hot hardness study should preferably be conducted in combination with metal cutting tests to further verify the dependence of hot hardness on the flank wear resistance. 

[1] O. Knotek, M. Bohmer and T. Leyendecker, Journal of V acuum Science and Technology A 4 (1986) 2695.

[2] H.A. Jehn, S. Hofmann, V.E. Ruckborn and W.D. Munz, Journal of V acuum Science and Technology A 4 (1986) 2701.

[3] J.C. Knight, Wear 138 (1990) 239.

[4] B. Navinšek, P. Panjan and A. Cvelbar, Surface and Coatings Technology 74-75 (1995) 155.

[5] A. Hörling, L. Hultman, M. Odén, J. Sjölén and L. Karlsson, Journal of Vacuum Science and Technology A 20 (2002) 1815.

[6] P.H. Mayrhofer, A. Hörling, L. Karlsson, J. Sjölén, T. Larsson, C. Mitterer and L. Hultman, Applied Physics Letters 83 (2003) 2049.

[7] R. Rachbauer, E. Stergar, S. Massl, M. Moser and P.H. Mayrhofer, Scripta Materialia 61 (2009) 725.

[8] A. Knutsson, M.P. Johansson, P.O.Å Persson, L. Hultman and M. Odén, Applied Physics Letters 93 (2008) 143110.

[9] R. Rachbauer, S. Massl, E. Stergar, D. Holec, D. Kiener, J. Keckes, J. Patscheider, M. Stiefel, H. Leitner and P.H. Mayrhofer, Journal of Applied Physics 110 (2011) 023515.

[10] L.J.S. Johnson, M. Thuvander, K. Stiller, M. Odén and L. Hultman, Thin Solid Films 520 (2012) 4362. 
[11] A. Knutsson, J. Ullbrand, L. Rogström, N. Norrby, L.J.S. Johnson, L. Hultman, J. Almer, M.P. Johansson-Jõesaar, B. Jansson and M. Odén, Journal of Applied Physics 113 (2013) 213518.

[12] A. Hörling, L. Hultman, M. Odén, J. Sjölén and L. Karlsson, Surface and Coatings Technology 191 (2005) 384.

[13] K.D. Bouzakis, G. Skordaris, S. Gerardis, G. Katirtzoglou, S.

Makrimallakis, M. Pappa, E. Lill and R. M'Saoubi, Surface and Coatings

Technology 204 (2009) 1061.

[14] R. M'Saoubi and S. Ruppi, CIRP Annals - Manufacturing Technology 58 (2009) 57.

[15] N. Norrby, M.P. Johansson, R. M'Saoubi and M. Odén, Surface and Coatings Technology 209 (2012) 203.

[16] J.D. Martin, S.J. Goettler, N. Fossé and L. Iton, Nature 419 (2002) 381.

[17] T. Komabayashi, Y. Fei, Y. Meng and V. Prakapenka, Earth and Planetary Science Letters 282 (2009) 252.

[18] S. Merkel, H. Liermann, L. Miyagi and H. Wenk, Acta Materialia 61 (2013) 5144.

[19] T. Uchida, Y. Wang, M.L. Rivers and S.R. Sutton, Journal of Geophysical Research B 106 (2001) 21799.

[20] K. Bhattacharya, S. Conti, G. Zanzotto and J. Zimmer, Nature 428 (2004) 55.

[21] M. Avrami, The Journal of Chemical Physics 7 (1939) 1103.

[22] M. Avrami, The Journal of Chemical Physics 8 (1940) 212.

[23] M. Avrami, The Journal of Chemical Physics 9 (1941) 177.

[24] W.A. Johnson and R.F. Mehl, Transactions AIME 135 (1939) 416.

[25] E. Jimenez-Melero, R. Blondé, M.Y. Sherif, V. Honkimäki and N.H. Van Dijk, Acta Materialia 61 (2013) 1154.

[26] B.J. Ganesh, S. Raju, A.K. Rai and M. Vijayalakshmi, Transactions of the Indian Institute of Metals 64 (2011) 93. 
[27] J. Huang, W.J. Poole and M. Militzer, Metallurgical and Materials Transactions A 35 A (2004) 3363.

[28] N. Liu, Y. Yu, Y. Cui, H. Zhang and Z. Mo, Journal of Applied Polymer Science 70 (1998) 2371.

[29] A. Khatibi, J. Lu, J. Jensen, P. Eklund and L. Hultman, Surface and Coatings Technology 206 (2012) 3216.

[30] E.A. Jägle and E.J. Mittemeijer, Acta Materialia 59 (2011) 5775.

[31] D. Molnar, C. Niedermeier, A. Mora, P. Binkele and S. Schmauder, Continuum Mechanics and Thermodynamics 24 (2012) 607.

[32] A.J. Bradley, Proceedings of the Physical Society 52 (1940) 80.

[33] M. Hillert. A theory of nucleation for solid metallic solutions, Dissertation Thesis, Massachusetts Institute of Technology, 1956.

[34] J.W. Cahn, Acta Metallurgica 9 (1961) 795.

[35] J.W. Cahn, Acta Metallurgica 10 (1962) 179.

[36] J.W. Cahn, Acta Metallurgica 14 (1966) 1685.

[37] P.H. Leo and W.C. Johnson, Acta Materialia 49 (2001) 1771.

[38] D.A. Porter, K.E. Easterling and M.Y. Sherif. Phase Transformations in Metals and Alloys, London: Taylor \& Francis, 2009.

[39] ASM Handbook. Vol. 8 - Mechanical Testing and Evaluation, Ohio: ASM International, 2000.

[40] D. Hull and D.J. Bacon. Introduction to Dislocations, Oxford: Butterworth Heinemann, 2001.

[41] E.O. Hall, Proceedings of the Physical Society B 64 (1951) 747.

[42] E.O. Hall, Nature 173 (1954) 948.

[43] N.J. Petch, Progress in Metal Physics 5 (1954) 1.

[44] H.W. Paxton and A.H. Cottrell, Acta Metallurgica 2 (1954) 3. 
[45] R.L. Fleischer, Acta Metallurgica 9 (1961) 996.

[46] R.L. Fleischer, Acta Metallurgica 11 (1963) 203.

[47] P.D. Merica, Journal of the Franklin Institute 234 (1942) 137.

[48] H. Gleiter and E. Hornbogen, Materials Science and Engineering 2 (1968) 285.

[49] J. Vyskočil and J. Musil, Surface and Coatings Technology 43-44 (1990) 299.

[50] J. Vyskočil and J. Musil, Journal of V acuum Science and Technology A 10 (1992) 1740 .

[51] J. Musil and J. Vlček, Surface and Coatings Technology 112 (1999) 162.

[52] D.M. Mattox, Metal Finishing 100 (2002) 394.

[53] A. Anders. Cathodic arcs - From Fractal Spots to Energetic Condensation, New York: Springer, 2008.

[54] A. Anders, Vacuum 67 (2002) 673.

[55] R.L. Boxman and S. Goldsmith, Surface and Coatings Technology 33 (1987) 153.

[56] H. Oettel, R. Wiedemann and S. Preißler, Surface and Coatings Technology 74-75, Part 1 (1995) 273.

[57] A. Knutsson, M.P. Johansson, L. Karlsson and M. Odén, Journal of Applied Physics 108 (2010) 044312.

[58] A. Knutsson, M.P. Johansson, L. Karlsson and M. Odén, Surface and Coatings Technology 205 (2011) 4005.

[59] A. Knutsson, I.C. Schramm, K. Asp Grönhagen, F. Mücklich and M. Odén, Journal of Applied Physics 113 (2013)

[60] A. Anders, Thin Solid Films 518 (2010) 4087.

[61] P.B. Barna and M. Adamik, Thin Solid Films 317 (1998) 27.

[62] M. Odén, C. Ericsson, G. Håkansson and H. Ljungcrantz, Surface and Coatings Technology 114 (1999) 39. 
[63] C.V. Falub, A. Karimi, M. Ante and W. Kalss, Surface and Coatings Technology 201 (2007) 5891.

[64] A. Karimi and W. Kalss, Surface and Coatings Technology 202 (2008) 2241.

[65] C. Wüstefeld, D. Rafaja, V. Klemm, C. Michotte and M. Kathrein, Surface and Coatings Technology 205 (2010) 1345.

[66] M. Ahlgren and H. Blomqvist, Surface and Coatings Technology 200 (2005) 157.

[67] A.R. Shetty and A. Karimi, Applied Surface Science 258 (2011) 1630.

[68] A.R. Shetty and A. Karimi, Thin Solid Films 528 (2013) 255.

[69] B. Alling, P. Steneteg, C. Tholander, F. Tasnádi, I. Petrov, J.E. Greene and L. Hultman, Physical Review B 85 (2012) 245422.

[70] I.G. Brown, Annual Review of Materials Science 28 (1998) 243.

[71] H. Ljungcrantz, L. Hultman, J. Sundgren, G. Håkansson and L. Karlsson, Surface and Coatings Technology 63 (1994) 123.

[72] A. Anders, Surface and Coatings Technology 120-121 (1999) 319.

[73] P.J. Martin and A. Bendavid, Thin Solid Films 394 (2001) 1.

[74] F.A. Soliman, O.A. Abu-Zeid and M. Merdan, Wear 119 (1987) 199.

[75] H. Holleck, Surface and Coatings Technology 36 (1988) 151.

[76] P.H. Mayrhofer, D. Music and J.M. Schneider, Applied Physics Letters 88 (2006) 071922.

[77] A. Hörling. Thermal Stability and Age Hardening of TiN-based Thin Films, Dissertation Thesis, Linköping University, 2005.

[78] F. Tasnádi, I.A. Abrikosov, L. Rogström, J. Almer, M.P. Johansson and M. Odén, Applied Physics Letters 97 (2010) 231902.

[79] C. Zener. Elasticity and anelasticity of metals, Chicago: University of Chicago Press, 1948. 
[80] I. Baker, R.K. Zheng, D.W. Saxey, S. Kuwano, M.W. Wittmann, J.A. Loudis, K.S. Prasad, Z. Liu, R. Marceau, P.R. Munroe and S.P. Ringer, Intermetallics 17 (2009) 886.

[81] B. Sonderegger and E. Kozeschnik, Scripta Materialia 66 (2012) 52.

[82] R. Forsén, M.P. Johansson, M. Odén and N. Ghafoor, Journal of Vacuum Science and Technology A 30 (2012) 061506.

[83] H. Lind, R. Forsén, B. Alling, N. Ghafoor, F. Tasnádi, M.P. Johansson, I.A. Abrikosov and M. Odén, Applied Physics Letters 99 (2011) 091903.

[84] D. Holec, L. Zhou, R. Rachbauer and P.H. Mayrhofer, Journal of Applied Physics 113 (2013) 113510.

[85] R. Rachbauer, D. Holec and P.H. Mayrhofer, Surface and Coatings Technology 211 (2012) 98.

[86] H. Riedl, D. Holec, R. Rachbauer, P. Polcik, R. Hollerweger, J. Paulitsch and P.H. Mayrhofer, Surface and Coatings Technology 235 (2013) 174.

[87] H. Lind, F. Tasnádi and I.A. Abrikosov, New Journal of Physics 15 (2013) 095010 .

[88] R. Rachbauer, A. Blutmager, D. Holec and P.H. Mayrhofer, Surface and Coatings Technology 206 (2012) 2667.

[89] I.A. Saladukhin, G. Abadias, A. Michel, S.V. Zlotski, V.V. Uglov, G.N. Tolmachova and S.N. Dub, Thin Solid Films 538 (2013) 32.

[90] B. Yang, L. Chen, Y.X. Xu, Y.B. Peng, J.C. Fen, Y. Du and M.J. Wu, International Journal of Refractory Metals and Hard Materials 38 (2013) 81.

[91] R. Forsén, M.P. Johansson, M. Odén and N. Ghafoor, Thin Solid Films 534 (2013) 394.

[92] B. Alling, M. Odén, L. Hultman and I.A. Abrikosov, Applied Physics Letters 95 (2009) 181906.

[93] D. Holec, F. Rovere, P.H. Mayrhofer and P.B. Barna, Scripta Materialia 62 (2010) 349.

[94] L. Vegard, Zeitschrift für Physike 5 (1921) 17. 
[95] L. Rogström, J. Ullbrand, J. Almer, L. Hultman, B. Jansson and M. Odén, Thin Solid Films 520 (2012) 5542.

[96] B. Alling, A.V. Ruban, A. Karimi, O.E. Peil, S.I. Simak, L. Hultman and I.A. Abrikosov, Physical Review B 75 (2007) 045123.

[97] F. Peng, D. Chen, H. Fu and X. Cheng, Physica B 403 (2008) 4259.

[98] L. Bayarjargal and B. Winkler, Applied Physics Letters 100 (2012) 021909.

[99] W. Feng, S. Cui, H. Hu, W. Zhao and Z. Gong, Physica B 405 (2010) 555.

[100] A. Siegel, K. Parlinski and U.D. Wdowik, Physical Review B 74 (2006) 104116.

[101] M. Birkholz. Thin Film Analysis by X-Ray Scattering, Weinheim: WileyVCH, 2006.

[102] A. Guinier, Nature 142 (1938) 569.

[103] G. Beaucage and D.W. Schaefer, Journal of Non-Crystalline Solids 172-174 (1994) 797.

[104] J. Ilavsky and P.R. Jemian, Journal of Applied Crystallography 42 (2009) 347.

[105] G. Beaucage, Journal of Applied Crystallography 28 (1995) 717.

[106] M. Odén, L. Rogström, A. Knutsson, M.R. Terner, P. Hedström, J. Almer and J. Ilavsky, Applied Physics Letters 94 (2009) 053114.

[107] D.B. Williams and C.B. Carter. Transmission Electron Microscopy, New York: Plenum Press, 1996.

[108] D.J. Smith, Microscopy and Microanalysis 14 (2008) 2.

[109] M.A. O'Keefe, Ultramicroscopy 108 (2008) 196.

[110] P.C. Tiemeijer, M. Bischoff, B. Freitag and C. Kisielowski, Ultramicroscopy 114 (2012) 72.

[111] T. Ishitani, T. Yamanaka, K. Inai and K. Ohya, V acuum 84 (2010) 1018.

[112] K. Ohya, T. Yamanaka, K. Inai and T. Ishitani, Nuclear Instruments and Methods in Physics Research B 267 (2009) 584. 
[113] R.M. Langford and A.K. Petford-Long, Journal of V acuum Science and Technology A 19 (2001) 2186.

[114] W.C. Oliver and G.M. Pharr, Journal of Materials Research 7 (1992) 1564.

[115] A.W. Lawson and T. Tang, Review of Scientific Instruments 21 (1950) 815.

[116] J.C. Jamieson, A.W. Lawson and N.D. Nachtrieb, Review of Scientific Instruments 30 (1959) 1016.

[117] H.T. Hall, Review of Scientific Instruments 29 (1958) 267.

[118] J. Lin, J. Shu, H. Mao, R.J. Hemley and G. Shen, Review of Scientific Instruments 74 (2003) 4732.

[119] C. Narayana, R.G. Greene and A.L. Ruoff, Journal of Physics 121 (2008)

[120] L. Yang, A. Karandikar and R. Boehler, Review of Scientific Instruments 83 (2012) 063905.

[121] H.E. Lorenzana, M. Bennahmias, H. Radousky and M.B. Kruger, Review of Scientific Instruments 65 (1994) 3540.

[122] L. Dubrovinsky, T.B. Ballaran, K. Glazyrin, A. Kurnosov, D. Frost, M. Merlini, M. Hanfland, V.B. Prakapenka, P. Schouwink, T. Pippinger and N. Dubrovinskaia, High Pressure Research 30 (2010) 620.

[123] N. Dubrovinskaia and L. Dubrovinsky, Review of Scientific Instruments 74 (2003) 3433.

[124] L. Dubrovinsky, N. Dubrovinskaia, O. Narygina, I. Kantor, A. Kuznetzov, V.B. Prakapenka, L. Vitos, B. Johansson, A.S. Mikhaylushkin, S.I. Simak and I.A. Abrikosov, Science 316 (2007) 1880.

[125] L. Dubrovinsky, K. Glazyrin, C. McCammon, O. Narygina, E. Greenberg, S. Uebelhack, A.I. Chumakov, S. Pascarelli, V. Prakapenka, J. Bock and N. Dubrovinskaia, Journal of Synchrotron Radiation 16 (2009) 737.

[126] T.B. Ballaran, A. Kurnosov and D. Trots, High Pressure Research 33 (2013) 453.

[127] L. Dubrovinsky and N. Dubrovinskaia. in: High-Pressure Crystallography, Amsterdam: Kluwer Academic Publishers, 2004, pp. 393-410. 
[128] L. Dubrovinsky, T.B. Ballaran, K. Glazyrin, A. Kurnosov, D. Frost, M. Merlini, M. Hanfland, V.B. Prakapenka, P. Schouwink, T. Pippinger and N. Dubrovinskaia, High Pressure Research 30 (2010) 620.

[129] H.K. Mao, P.M. Bell, J.W. Shaner and D.J. Steinberg, Journal of Applied Physics 49 (1978) 3276.

[130] J.C. Chervin, C. Power and A. Polian, High Pressure Research 25 (2005) 97.

[131] Q. Wei, N. Dubrovinskaia and L. Dubrovinsky, Journal of Applied Physics 110 (2011) 043513.

[132] J.D. Barnett, S. Block and G.J. Piermarini, Review of Scientific Instruments 44 (1973) 1.

[133] R.C. Liebermann, High Pressure Research 31 (2011) 493.

[134] D. O’Sullivan and M. Cotterell, Journal of Materials Processing Technology 118 (2001) 301.

[135] D. Biermann, M. Kirschner, K. Pantke, W. Tillmann and J. Herper, Surface and Coatings Technology 215 (2013) 376.

[136] W. Tillmann, E. Vogli, J. Herper, D. Biermann and K. Pantke, Journal of Materials Processing Technology 210 (2010) 819.

[137] S.B. Hosseini, T. Beno, S. Johansson, U. Klement, J. Kaminski and K. Ryttberg, Experimental Mechanics (2013) 1.

[138] H. Chandrasekaran and A. Thuvander, Machining Science and Technology 2 (1998) 355.

[139] R. M'Saoubi and H. Chandrasekaran, International Journal of Advanced Manufacturing Technology 56 (2011) 865.

[140] R. M'Saoubi and H. Chandrasekaran, International Journal of Machine Tools and Manufacture 44 (2004) 213.

[141] R. M'Saoubi, C. Le Calvez, B. Changeux and J.L. Lebrun, Proceedings of the Institution of Mechanical Engineers B 216 (2002) 153.

[142] A. Liljerehn, V. Kalhori and M. Lundblad, Machining Science and Technology 13 (2009) 488. 
[143] N.A. Abukhshim, P.T. Mativenga and M.A. Sheikh, Proceedings of the Institution of Mechanical Engineers B 218 (2004) 889.

[144] K.D. Bouzakis, N. Michailidis, N. Vidakis, K. Eftathiou, S. Kompogiannis and G. Erkens, CIRP Annals - Manufacturing Technology 49 (2000) 65.

[145] T. Özel, Journal of Materials Processing Technology 209 (2009) 5167.

[146] L. Xie, J. Schmidt, C. Schmidt and F. Biesinger, Wear 258 (2005) 1479.

[147] J.P. Davim. Machining of Hard Materials, London: Springer-Verlag, 2011.

[148] P.A. Dearnley and E.M. Trent, Metals Technology 9 (1982) 60.

[149] B.M. Kramer and N.P. Suh, Journal of Engineering for Industry 102 (1980) 303.

[150] B.V. Manoj Kumar, J.R. Kumar and B. Basu, International Journal of Refractory Metals and Hard Materials 25 (2007) 392.

[151] C.Y.H. Lim, S.C. Lim and K.S. Lee, Wear 225-229 (1999) 354.

[152] S. Ruppi and M. Halvarsson, Thin Solid Films 353 (1999) 182.

[153] S. Ruppi, B. Högrelius and M. Huhtiranta, International Journal of Refractory Metals and Hard Materials 16 (1998) 353.

[154] ISO 3685: Tool-life Testing with Single-point Turning Tools, Geneva: International Organization for Standardization, 1993.

[155] A. Flink, R. M'Saoubi, F. Giuliani, J. Sjölén, T. Larsson, P.O.Å Persson, M.P. Johansson and L. Hultman, Wear 266 (2009) 1237.

[156] H.O. Gekonde and S.V. Subramanian, Surface and Coatings Technology 149 (2002) 151.

[157] A. Molinari and M. Nouari, Wear 252 (2002) 135.

[158] P.P. Chattopadhyay, S.K. Pabi and I. Manna, Materials Chemistry and Physics 68 (2001) 80.

[159] S. Korte, R.J. Stearn, J.M. Wheeler and W.J. Clegg, Journal of Materials Research 27 (2012) 167. 
[160] G.S. Fox-Rabinovich, B.D. Beake, J.L. Endrino, S.C. Veldhuis, R.

Parkinson, L.S. Shuster and M.S. Migranov, Surface and Coatings Technology 200 (2006) 5738.

[161] J. Milhans, D.S. Li, M. Khaleel, X. Sun, M.S. Al-Haik, A. Harris and H. Garmestani, Journal of Power Sources 196 (2011) 5599. 



\section{Papers}

The articles associated with this thesis have been removed for copyright reasons. For more details about these see:

http://urn.kb.se/resolve?urn=urn:nbn:se:liu:diva-106507 